\title{
العلاقة بين الاستدلال بعدم الدليل الشرعي وبين استصحاب العدم الأصلي الغيل (دراسة أصولية)
}

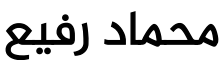

جامعة سيدي محمد بن عبد الله بفاس- المغرب Mohamad.rafia@usmba.ac.ma
عبد الغفور العمراوي

جامعة سيدي محمد بن عبد الله بفاس- المغرب abdelghafourelameraouy@gmail.com 


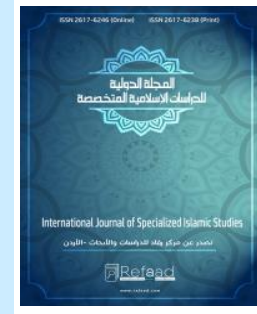

$$
\text { العلاقة بين الاستدلال بعدم الدليل الشرعي وبين استصحاب العدم الأصلي (دراسة أصهولية) }
$$

\author{
عبد الغفور العمراوي \\ جامعة سيدي محمد بن عبد الله بفاس- المغرب
}

abdelghafourelameraouy@gmail.com

$$
\text { جامعة سيدي محمد بن عبد الله بفاس- المغرب رفيع }
$$

Mohamad.rafia@usmba.ac.ma

DOI: https://doi.org/10.31559/SIS2021.6.2.4 2021/10/26: 2021/10/2 مراجعة البحث: قبول البحث البحث: 20210/12

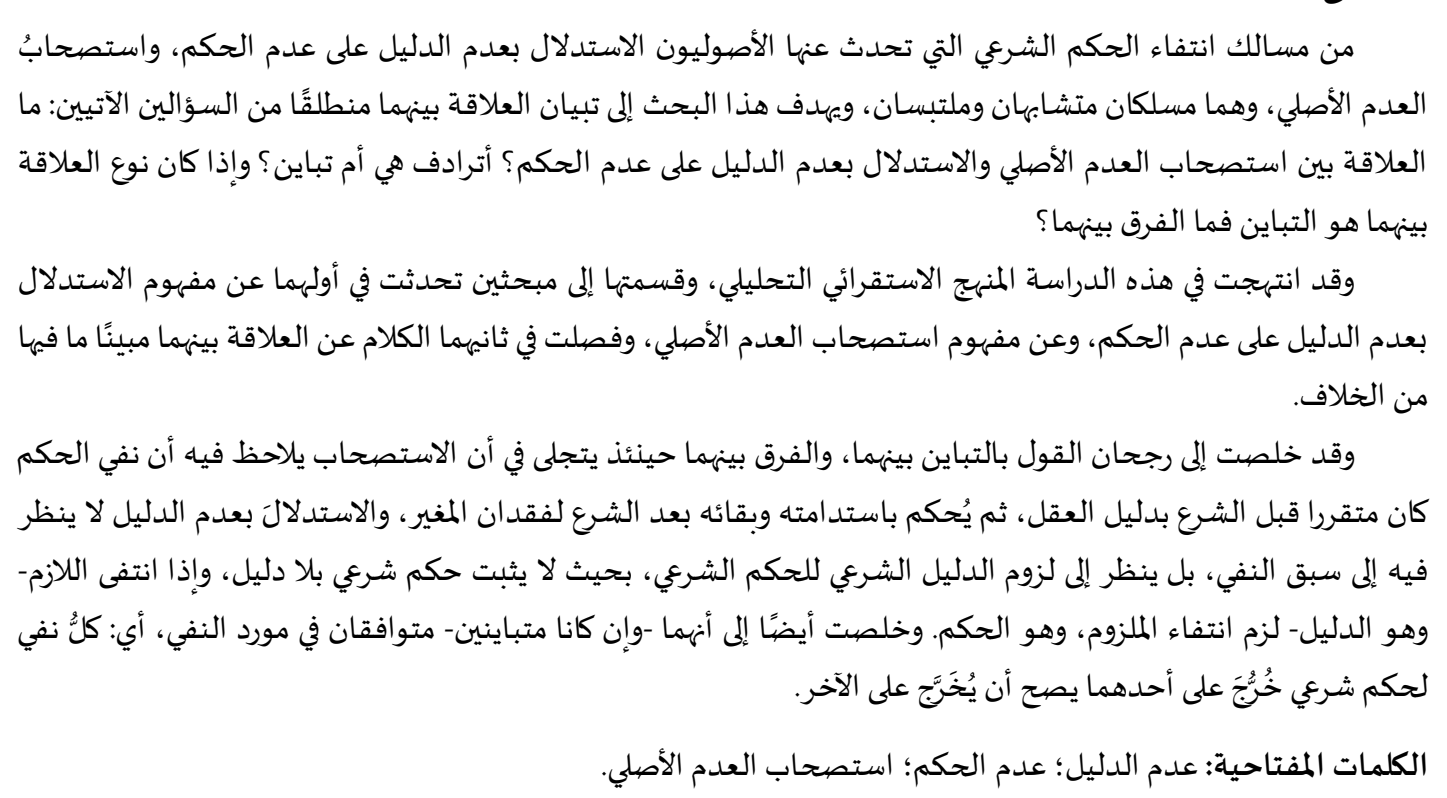

الحمد الله رب العالمين، ولا حول ولا قوة إلا بالله العلي العظيم، والصلاة والسلام على سيدنا محمد خاتم النبيين، وعلى آله وصحبه

وبعد، فإن النظر والبحث في الأحكام الشرعية إما في إثباتها وإما في نفيها، ولا بد لكليهما من مسالك، وقد ضبط علماء أصول الفقه

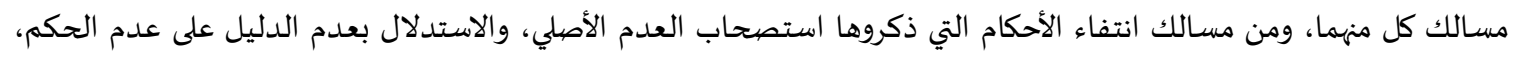
والمقارن بين هذين المسلكين يدرك أن بينهما مشابهة قوية؛؛ إذ يلتقيان في نتيجة واحدة، وهي عدماء الحمات الحكم الشرعي، فلذا عزمت مستعينًا 
بالله على دراسة العلاقة بينهما، وقد وسمت هذه الدراسة بهذا العنوان: "العلاقة بين الاستدلال بعدم الدليل الشرعي وبين استصحاب العدم الأصلي دراسة أصولية".

مشكلة الدراسة:

تتجلى إشكالية الدراسـة في العلاقة بين استصحاب العدم الأصلي والاستدلال بعدم الدليل على عدم الحكم، ويمكن توضيحها بالسؤالين الآتيين: ما العلاقة بين استصحاب العدم الأصلي والاستدلال بعدم الدليل؟ أترادف هي أم تباين؟ وإذا كان نوع العلاقة بينهما

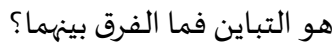
الدراسـات السـابقة:

لم أجد بعد البحث دراسـة مستقلة في هذا الموضوع، لكن وقفت على ثلاث دراسات معاصرة تناول فيها أصحابها الموضوع باختصار: الأولى: الاستدلال بعدم الدليل على عدم الحكم وما يتخرج عليه، إعداد الباحث رضيوان عبد الرب السروري، وهو رسالة جامعية لنيل درجة الماجستير بجامعة أم درمان الإسلامية. الثانية: مسألة الاحتجاج بعدم الدليل، إعداد الدكتور خالد بن محمد العروسي، وهو بحث منشور بمجلة الجامعة الإسلامية، العدد 151. الثالثة: حلي التراقي من مكنون جواهر المراقي، تأليف الشيخ محمد فال (أباه) بن عبد الله العلوي الشنقيطي، وهو شرح على منظومة مراقي السعود في علم أصول الفقاه. وبعد قراءتي للموضوع في هذه الدراسات الثلاثة لاحظت أنها تناولت الموضيوع باختصار، وأن نتائجها متباينة، ولأجل هذا وذاك عقدت العزم على إعادة دراستاه مع مناقشة ما في تلك الدراسات من نتائج. منهج الدراسـة: اعتمدت في بناء هذه الدراسة على المنهج الاستقرائي التحليلي، حيث قمت بتتبع مفردات البحث في مظانها، ثم أعقبت ذلك

بالتحليل والمقارنة.

خطة الدراسة:

قسمت البحث إلى مبحثين تسبقهما مقدمة وتلحقهما خاتمة:

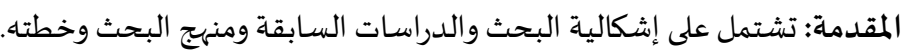

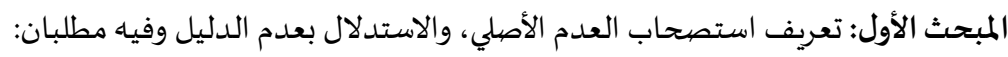

$$
\begin{aligned}
& \text { المطلب الأول: تعريف استصحاب العدم الأصلي } \\
& \text { المطلب الثاني: تعريف الاستدلال بعدم الدليل }
\end{aligned}
$$

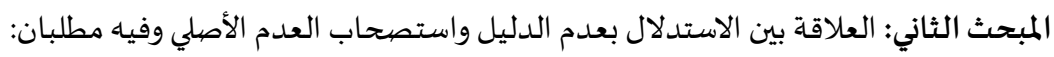
المطلب الأول: بيان الخلاف في العلاقة بين الاستدلال بعدم الدليل واستصحاب العدم الأصلي المطلب الثاني: مناقشة وترجيح الخاتمة: تشتمل على خلاصية النتائج

\section{المبحث الأول: تعريف استصحاب العدم الأصلي والاستدلال بعدم الدليل}

لا يمكن تصهور العلاقة بين استصحاب العدم الأصلي والاستدلال بعدم الدليل دون تصور حقيقة كل منهما، فلذا عقدت هذا المبحث لتعريفهما، وقسمته إلى مطلبين:

$$
\text { المطلب الأول: تعريف استصحاب العدم الأصلي: }
$$
أولًا: تعريف الاستصحاب في اللغة:

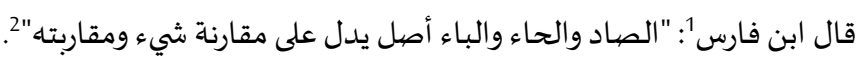

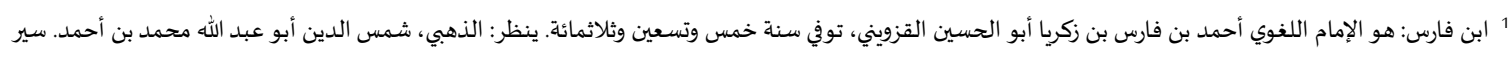

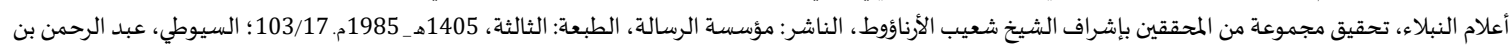

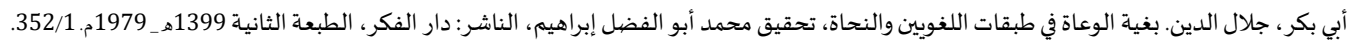

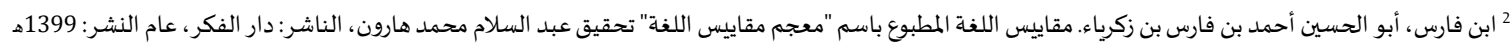


وقال ابن منظور3 " "واستصحب الرجلَ دعاه إلى الصحبة، وكل ما لازم شيئا فقد استصحبه" مما سبق يتبين أن الاستصحاب في اللغة استفعال من الصحبة، ومعناه طلب الصحبة، وهي المالازمة، كالاستسقاء بمعنى طلب واهب السقي، والاستفهام لطلب الفهم. ثانيًا: الاستصححاب في الاصطلاح: قد عرف الأصوليون مصطلح الاستصحاب بتعاريف كثيرة، لكنها وإن اختلفت في المبنى متحدة أو متقاربة في المعنى، منها قولهم:

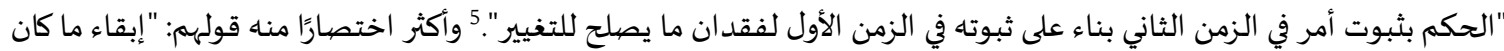
على ما كان عليه لانعدام المغير"

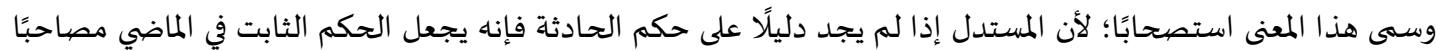
للحال، أو يجعل الحال مصياحبًا لذلك الحكمجا. إذا اتضح مفهوم الاستصحاب فليُعلم أنه جنس يشمل أكثر من نوع، وليس المقام مقام تفصيل لأنواعاه، بل المقصيود هنا نوع

$$
\text { ثالثًا: تعريف، وهو استصحاب العدم الأصلي. }
$$
سأكتفي في بيان استصحاب العدم الأصلي بكلام للإمام الغزاليه؛ فإنها أجود وأبسط ما رأيت في تصوير هذ النوع من الاستصحاب،

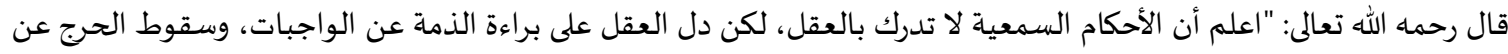
الخلق في الحركات والسكنات قبل بعثة الرسل - عليهم السلام - وتأييدهم بالمعجزات. وانتفاء الأحكام معلوم بدليل العقل قبل ورود السمح، ونحن على استصحاب ذلك إلى أن يرد السمح، فإذا ورد نبي وأوجب خمس صلوات فتبقى الصلاة السادسة غير واجبة لا بتصريح

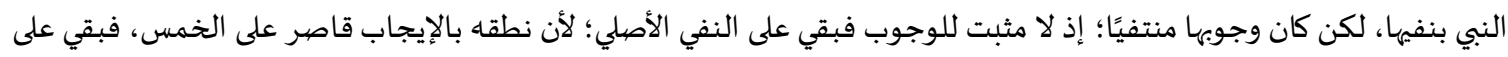

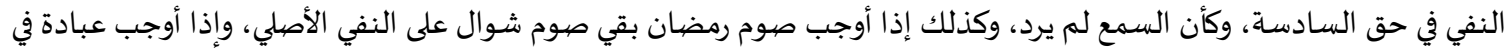

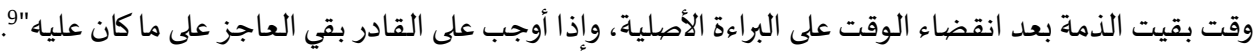

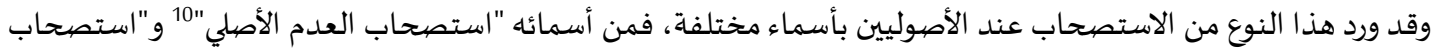
حال العقل"11 و "البراءة الأصلية"12 و"استصحاب البراءة الأصلية"13 و"استصحاب براءة الألذمة"14" و"استصحاب النفي الأصلي"15. وإذا أطلق لفظ الاستصحاب فإنها ينصرف إلى هذا النوع.16.

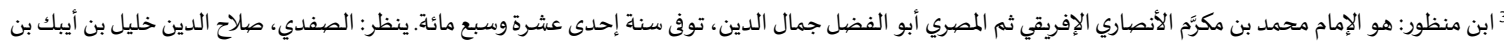

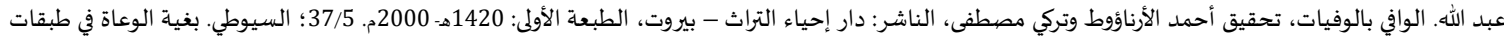

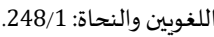

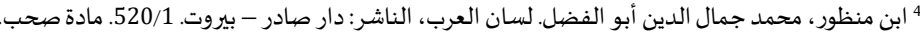

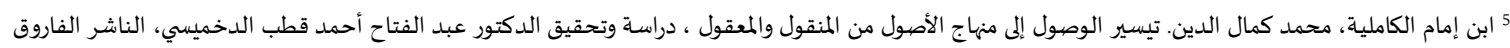

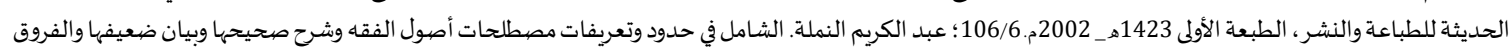

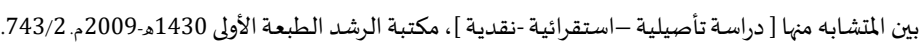

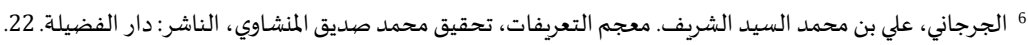

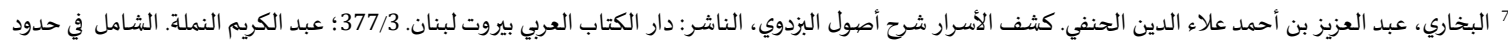
وتعريفات مصطلحات أصول الفقه: 743/2.

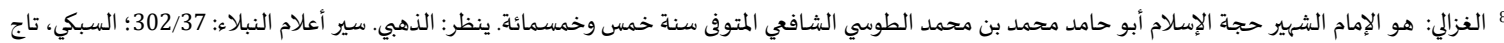

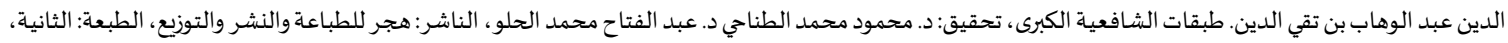

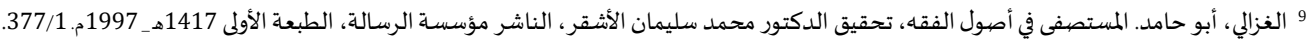

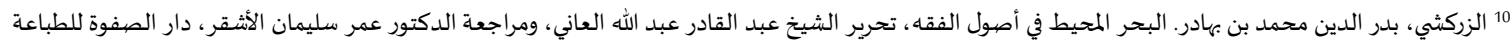
والنشر والتوزيع، الطبعة الثانية 1413هـ 1992م. 20/6.

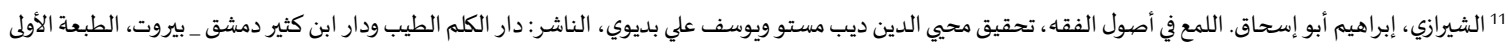

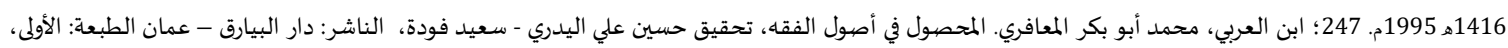

130.1999 1420 1420

12 القرافي، أحمد شهاب الدين بن إدريس. شرح تنقيح الفصول، الناشر: دار الفكر للطباعة والنشر والتوزيع. 352.

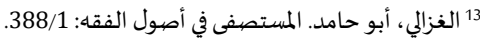

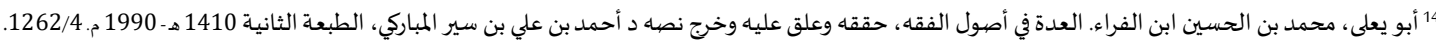

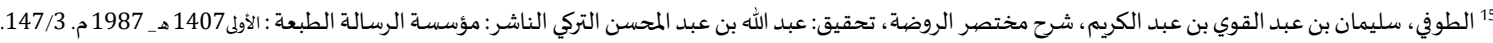
16 عبد الكريم النملة. الشامل في حدود وتعريفات مصطلح الفوي بندات علم أصول الفقه: 
المطلب الثاني: تعريف الاستدلال بعدم الدليل على عدم الحكم: لم أجد بعد البحث من بَيَّنَ صورة الاستدلال بعدم الدليل على عدم الحكم بالحدل أو الرسم، ولعل موجب عدم تعرضهمهم لتعريفه بالحد أو الرسم هو وضوحه،، لكن قد وردت عند بعض الأصهوليين والجدليين عبارات تكشف صئن هورتاه وتوضح حقيقته كما ورد التمثيل لـه، ومن أدق العبارات ما يلي: بالي: قال الإمام أبو الحسين البصري 17 1أن "أن يفقد الناظر بعد الفحص الشـديد دلِيلا على ذلك الحكم مع أنه لو كانَ ثابتًا لكان عليه

وقال الإمام الشيرازي 19: "ومما يلحق بأدلة الشرع الاستـلال بعدم الدليل في الشيء على نفيه، وذلك مثل أن يستدل الشـافعي على نفي زكاة الخضراوات بأن يقول: لو كانت الزكاة واجبة لكان عليها دليل من جهة الشرع، ولو كارئ كان على ذادلى ذلك دليل لعرفناه مع البحث، فلما

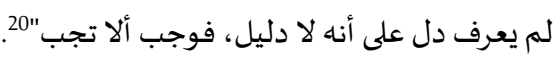

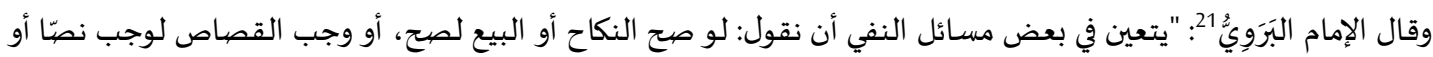

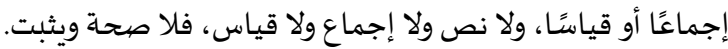

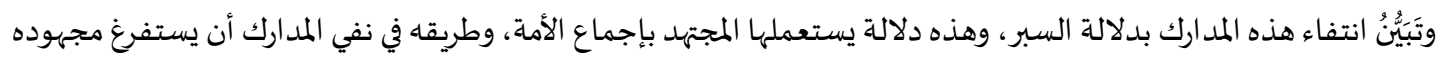

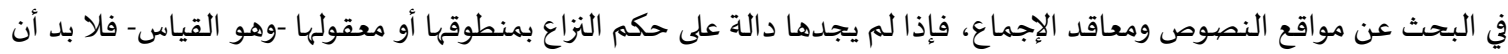

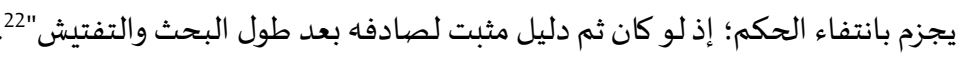
فمجموع هذه العبارات كاف في كشف صورة الاستدلال بعدم الدليل، ومنها يمكن أن نستنج مجموعة من الأمور: الأول: أن الحكم بعدم الدليل خاص بمن كان أهلاً لذلك، وهو المجتهد، وأما العامي فلا يجوز له ذلك. • الثاني: أن حكم المجتهد على الدليل بالعدم لا يكون إلا بعد الفحص الشديد والسبر البليغ لأدلة الثبوت. الثالث: ما أشـار إليه الشيرازي في تقرير مثال عدم الدليل حيث قال: "لو كانت الزكاة واجبة لكان عليها دليل من جهة الشرع". ومعنى هذا أن الدليل الشرعي لازم للحكم الشرعي، بحيث لا يمكن أن يوجد الحكم ولا دليل عليه؛ إذ يمتنع وجود الملزوم دون

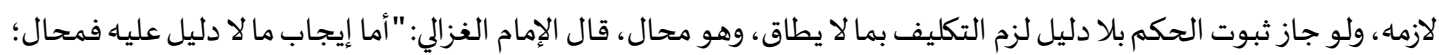

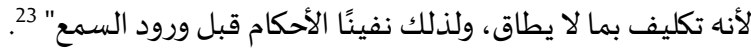
وهذا الذي ذكر من لازمية الدليل للحكم هو وجاه دلالة عدم الدليل على عدم الحكم؛ إذ نفي اللازم -وهو الدليل- يوجب نفي الملزوم، وهو الحكم. وبعد بيان المراد باستصحاب العدم الأصلي والاستدلال بعدم الدليل يظهر أنهما متشابهان، ووجه الشبه بينهما أهما يشتركان في النتيجة التي هي العدم، فعدم الحكم الذي أنتجه عدم الدليل هو العدم الأصلي المستصحب، وقداند صبرح الإمام ابن تيمية بالمشابهة

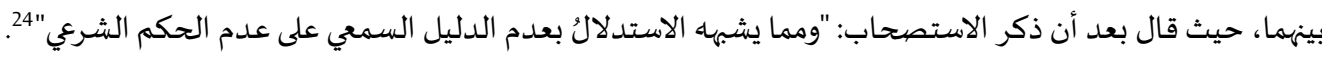
المبحث الثاني: العلاقة بين الاسـدلالال بعدم الدليل واستصحساب العدم الأصهلي لم أجد بعد البحث كلامًا صريحًا لمتقدمي الأصوليين في بيان العلاقة بين الاستدلال بعدم الدليل وبين استصحاب العدم الأصلي،

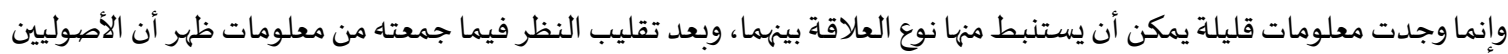

17 أبو الحسين البصري: هو الإمام محمد بن علي بن الطيب أبو الحسين البصري المعتزلي المتوفف سنة ست وثلاثين وأربعمائة. ينظر: الصفدي. الوافي بالوفيات: 92/4؛ الذهبي. سير أعلام النبلاء: 587/17. 18 أبو الحسين البصري، محمد النداء بن علي بن الطيب المعتزلي. المعتمد في أصول الفقه، اعتنى بتهذيبه وتحقيقه محمد حميد الله، طبعة المعهد العلمي الفرنسي للدراسات العربية بدمشق. 19 الإمام الشيرازي: هو الإمام إبراهيم بن علي بن يوسف الشيرازي الشافعي المتوفى سنة ست وسبعين وأربعمائة. ينظر: السبكي. طبقات الشافعية الكبرى: 215/4؛ الذهبي. سير أعلام النبلاء: 452/18. 20 الشيرازي، أبو إسحاق إبراهيم بن علي. الملخص في النياء الجدل في أصهول الفقه، رسالة ماجستير دراسة وتحقيق، إعداد الطالب محمد يوسف آخندجان نيازي، جامعة أم القرى كلية

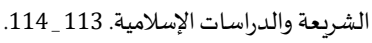

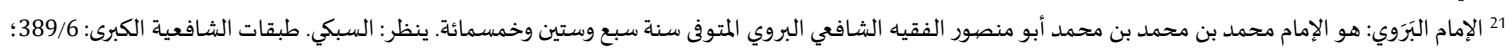
الذهبي. سير أعلام النبلاء: 32 البروي، محمد بن محمد الشافعي. المقترح في المصطلح، دراسة وتحقيق وتعليق د شريفة بنت علي بن سليمان الحوشاني، دار الوراق، الطبعة: الأولى 1424هـ ــ 2004م. 387 ـــ

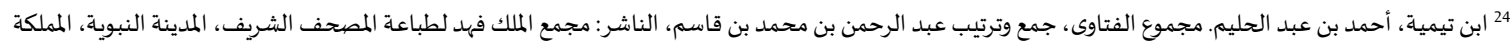

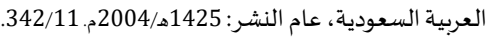




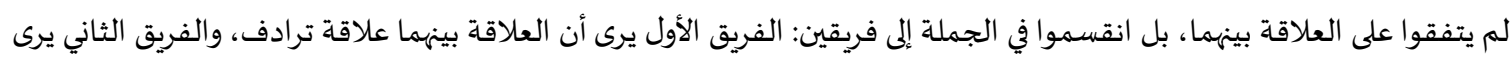
أهها علاقة تباين 25، وفي المطلبين الآتيين تفصيل لهذا الخهاف الخلاف مع بيان القول الراجح:

المطلب الأول: بيان الخلاف في العلاقة بين الاستدلال بعدم الدليل واستصحاب العدم الأصلي:

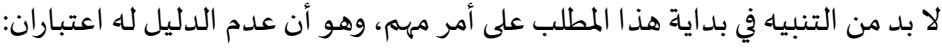

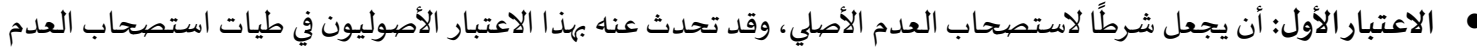

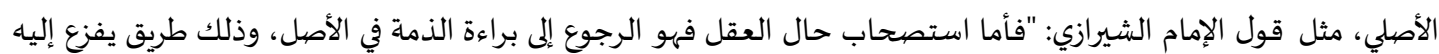

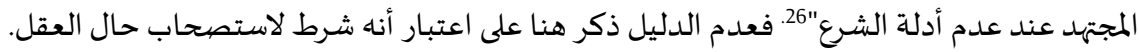

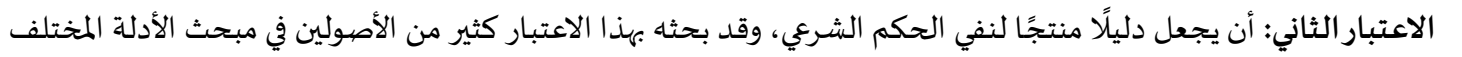

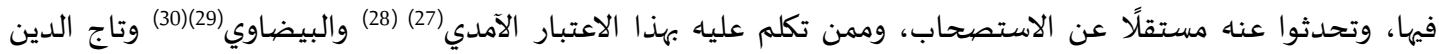

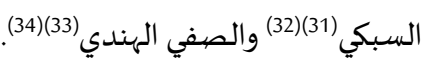
إذا تقرر هذان الاعتبارن فليُعلم أن عدم الدليل بالاعتبار الأول ليس عين الاستصحاب؛ لأنه شرط له، وواضيح أن الشرط غير

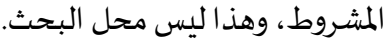

وأما بالاعتبار الثاني - وهو محل البحث- فهل يرادف الاستصحاب أم يباينه؟ وقع في ذلك خلاف يمكن إجمالي الديان في قولين: الأول:

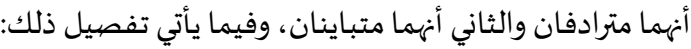

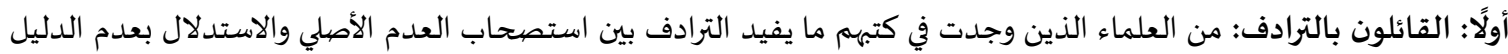

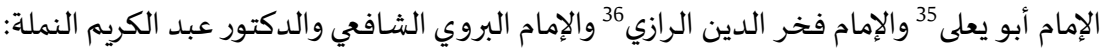

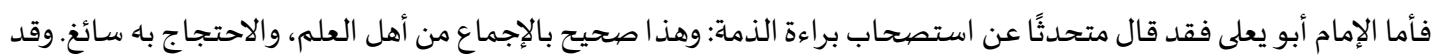

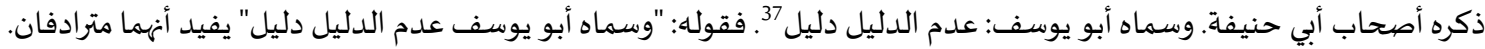

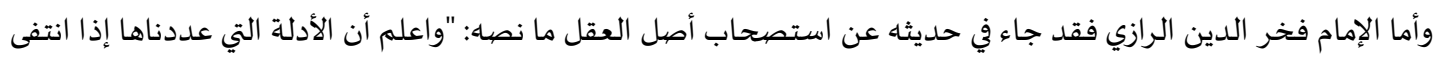

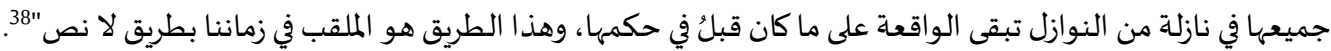

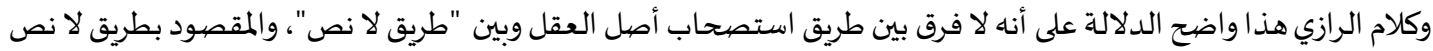

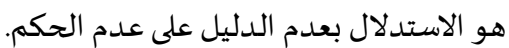

25

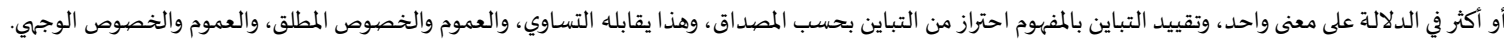

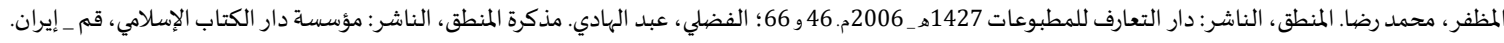

26 الشيرازي، أبو إسحاق. اللمع في أصول الفقه: 247.

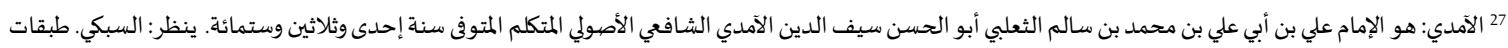

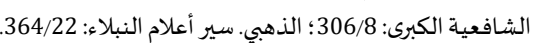

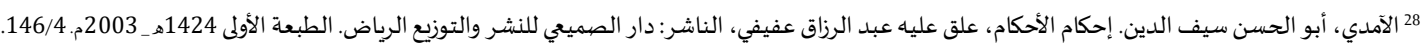

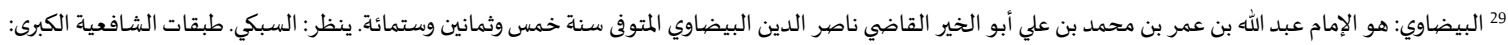

157/8؛ الصفدي. الوافي بالوفيات: 206/17.

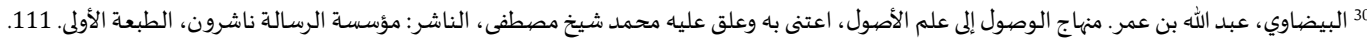

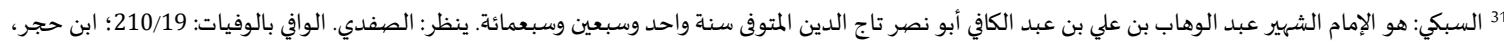

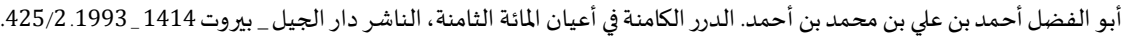

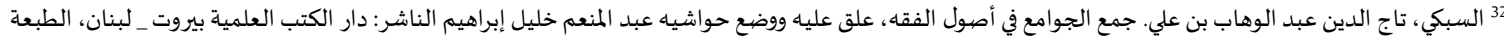

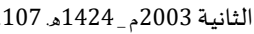
33 الصفي الهندي: هو الإمام محمد بن عبد 162 الهبد الرحيم بن محمد صفي الدين الهندي الأرموي الشافعي المتوفى سنة خمس عشرة وسبعمائة. ينظر: السبكي. طبقات الشافعية الكبرى:

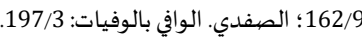

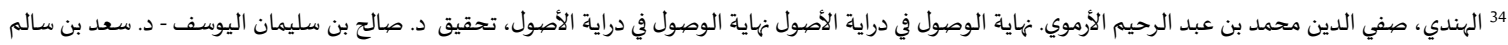

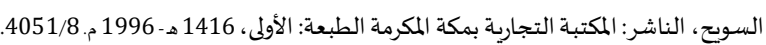

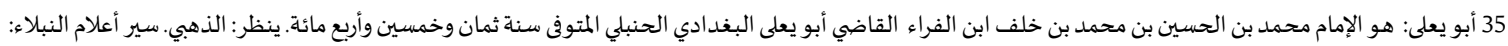

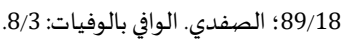
36 الرازي: هو الإمام الشهير محمد بن عمر أبو البو عبد الله فخر الدين الرازي الشافعي المتوفف سنة ست وستمائة. ينظر: السبكي. طبقات الشافعية: 81/8؛ الصفدي. الوافي بالوفيات: 
وأما الإمام البروي فإنه قال في سياق الحديث عن الاستدلال بانتفاء الدليل: "وهذا هو الذي سماه بعض الأصوليين استصحاب

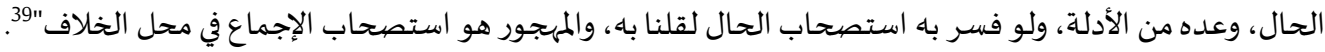

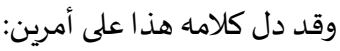

الأول: أن الاستدلال بعدم الدليل هو المسمى باستصحاب الحال عند بعض الأصدوليين.

الثاني: أن "استصحاب الحال" لو لم يطلق إلا على عدم الدليل لقال باه، ولكن لأنه صار مشتركًا بين عدم الدليل -وهو دليل معتبر - وبين استصحاب الإجماع في محل الخلاف -وهو غير معتبر - له يقل بهاه. وقد يخيل للناظر أن في قوله: "ولو فسر به استصحاب الحهاب الحال لقلنا به" تناقضا، وقد شعر المؤلف نفسـه بهذا التناقض المتخيل، فلذا أورده في شرح كتابه، وأجاب عنه فقال: "ربما يتخيل بعض المبتدئين فيه تناقضيا من حيث إنها أخبر أنه سماه بعض الأبهاه

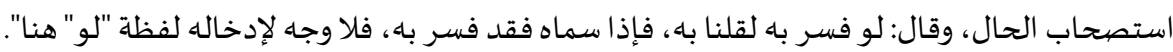
وقد أجاب عن هذا التناقض بكلام حاصله: أن من سماه استصحاب الحال لم يجعل الاسم مقصورا عليه، بل جعله مشتركا بينها وبين استصحاب الإجماع في محل الخلاف، ونظرا لأن المصطلح صار مشتركا بين أمرين أحدهما معتبر والآخر غير معتبر ، فإنه آثر عدم استعمال هذا المصطلح

وهذه المناقشة التي أوردها البروي يستفاد منها أنه لا فرق بين الاستدلال بعدم الدليل وبين استصحاب الحال إن أريد بها استصحاب العدم الأصلي، إلا أنه لا يرتضي استعمال مصطلح "استصحاب الحال" بسبب ما قد وقع فياه من الاشتراك بين ما هو معتبر وما هو غير معتبر. وأما الدكتور عبد الكريم النملة فقد نص على أن استصحاب البراءة الأصلية هو ما عبر عنه بعض العلماء بالاستدلال بعدم الدليل على عدم الحكم ب. ومقتضضى هذا أنه لا فرق بينهما.

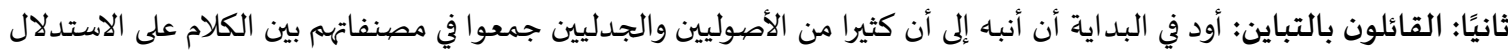
بعدم الدليل والكلام على استصحاب العدم الأصلي، وتحدثوا عن كل واحد منها بانفراد، وهذا مقتض للمباينة بينهما، وإلا فلو كانا اسمين لمسمى واحد ما تحدثوا عن كل واحد منهما مستقلًا عن الآخر. وقد ألفيت كلامًا يفيد التباين بينهما لدى الإمام أبي زيد الدبوسي 42 وشيخ الإسلام ابن تيمية 43 ولدى ثلاثة من المعاصرين: الشيخ

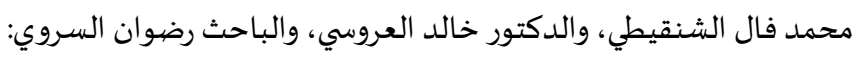

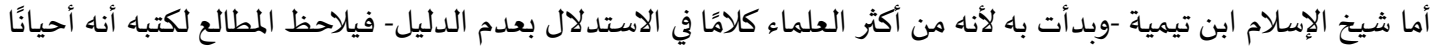

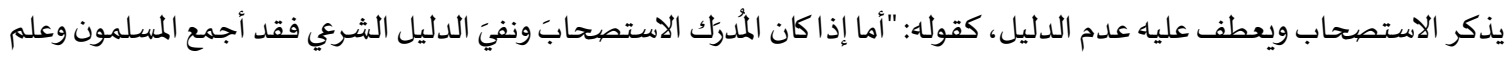
بالاضطرار من دين الإسلام أنه لا يجوز لأحد أن يعتقد ويفتي بموجب هذا الاستصحاب والنفي إلا بعد البحث عن الأدلة الخاصة إذا كان من أهل ذلك" والسؤال الذي يرد هنا هو: هل عطفه عدم الدليل على الاستصحاب من باب عطف أحد المترادفين على الآخر أم من باب عطف المتغايرين؟

الذي يدل عليه كلامه في مواضع متعددة هو الاحتمال الثاني، وسأذكر ثلاثة نصوص من كلامه تثبت هذه الدعوى: النص الأول: قوله مبينًا طرق الأحكام الشرعية: الطريق السادس: الاستصحاب، وهو البقاء على الأصل فيما لم يعلم ثبوته وانتفاؤه

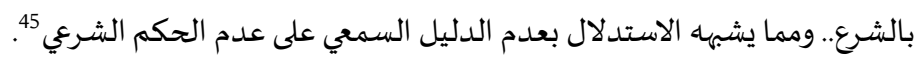
ووجاء دلالة هذا النص على مغايرة الاستدلال بعدم الدليل على عدم الحكم للاستصحاب في نظر ابن تيمية هو أنه شبهاه

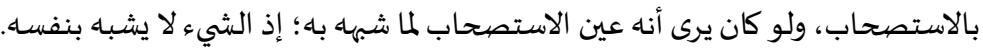

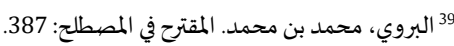
90

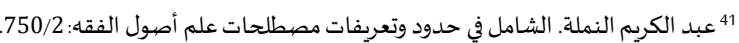

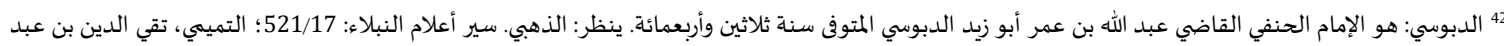

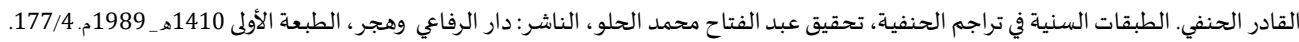

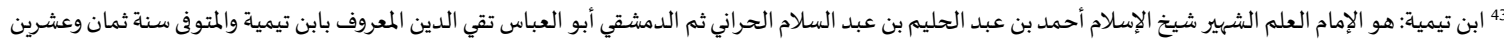

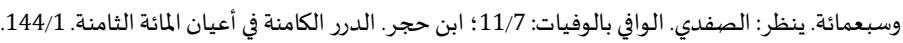

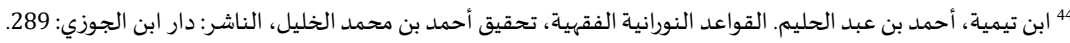

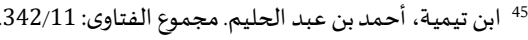


النص الثاني: قوله: لنفي الحكم ثلاث 46 مسالك: أحدها: التمسك بالاستصحاب المحض .. المسلك الثاني: أن نبين من أدلة الشرع العامة ما ينفي الوجوب والحرمة فيما لم يوجباء الشـارعُولم يحرماء. والمسلك الثالث أن يقال: الحكم الشرعي لا يثبت إلاّ بدليله، والدليل منتف،

ووجاه دلالة هذا النص على المقصود هو أنه عد المسالك ثلاثة، ولو كان الاستصحاب عين الاستدلال بعدم الدليل لحصبر المسالك في

النص الثالث: قوله بعد أن ذكر استصحاب الحال: "وقد يستدل على نفي الواجبات أو المحرمات بطريق آخر بأن يقال: الوجوب أو

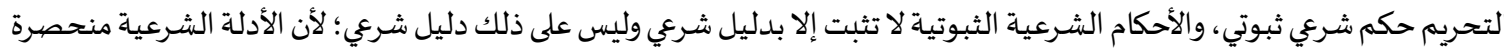
في الكتاب والسنة والإجماع والقياس وتوابع ذلك، وكلها منتفية في المسألة"

فقوله: "وقد يستدل على نفي الواجبات أو المحرمات بطريق آخر" واضح الدلالة على دعوى المغايرة بينهما. وأما الإمام الدبوسي فقد عقد في كتابه تقويم أصول الفقه بابًا بعنوان:" باب القول في جملة القائلين بلا دليل مع اعتقادهم بطانيان الاحتجاج به" وقال في مطلعاء: هؤلاء الرهط أربعة أقسام: المحتجون باستصحاب الحال، والمحتجون بتعارض الأشباه، والمستدلون

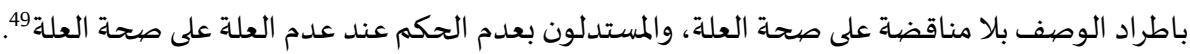

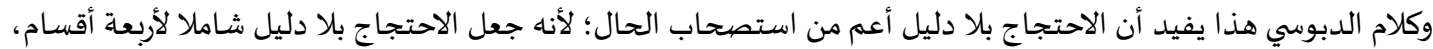

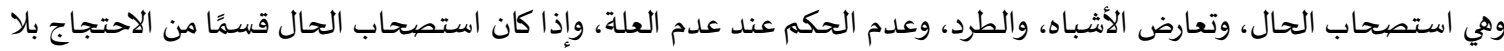
دليل فهو أخص منـه.

وقد وافق الدبوسيَ في جعل استصحاب الحال قسما من الاحتجاج بلا دليل السرخسيو(50) (51) والخبازيُ (52) (53.).

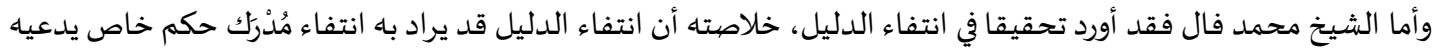

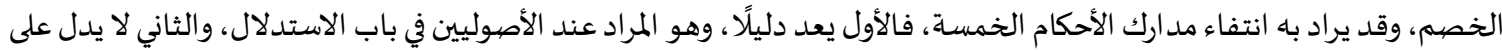

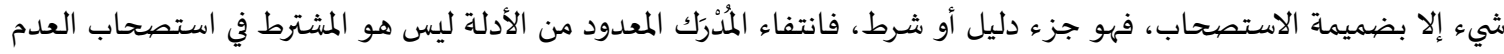

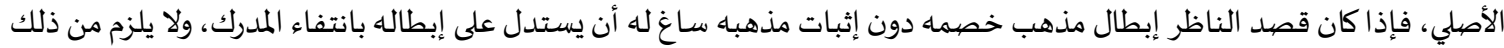

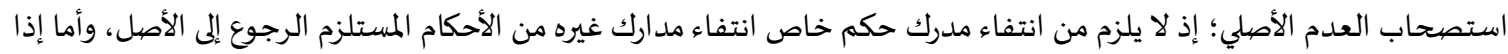
كان قصد الناظر إثبات حكم شري باستصحاب العدم الأصلي، فإن ذلك لا يتم له حتى ينفي مدارك الأحكام كلها، وقد ذكر جملة من النصوص الأصولية ليثبت بها هذا الفرق 54. وسيأتي في المطلب الآتي مناقشة هذا التحقيق. وأما الدكتور خالد العروسي فقد ذكر أن مسألة الاحتجاج بعدم الدليل شديدة الالتباس بالاستصحاب بنوعياه: التمسك بدليل

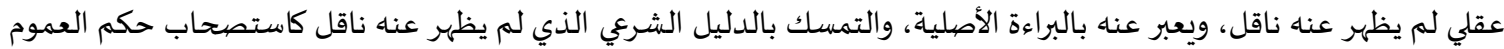

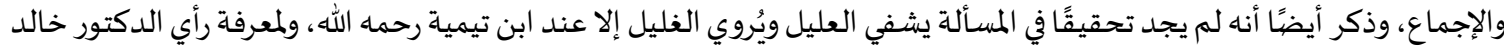

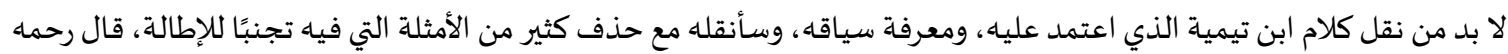
الله تعالى: عدم الدليل القطعي والظني على الشيء ليس دليلًا 55 على انتفائه إلا أن يعلم أن ثبوته مستلزم لذلك الدليل. مثل أن يكون

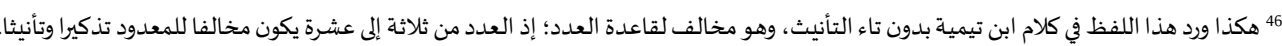

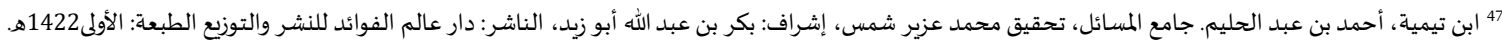
.284_283/2 48 ابن تيمية، أحمد بن عبد الحليم. تنبيه الرجل العاقل على تمويه الجدل الباطل، تحقيق علي بن محمد العمران ومحمد عزير شمس، إشراف بكر بن عبد الله أبو زيد، دار عالم الفوائد. 619/2.

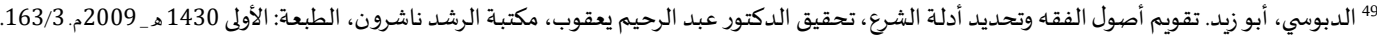

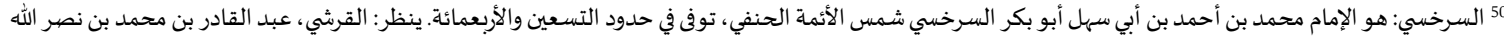

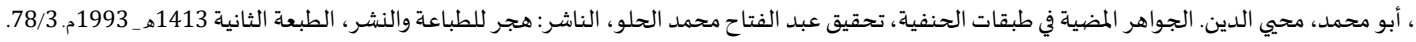

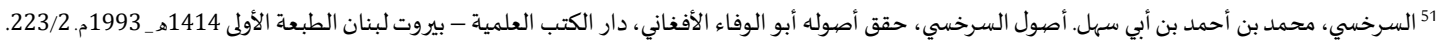

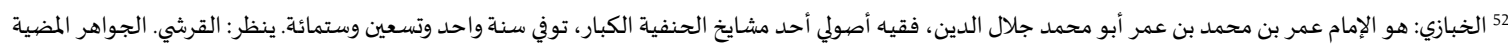

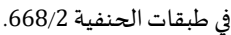
53 الخبازي، جلال الدين أبو محمد عمر. المفني في أصول الفقهه، تحقيق الدكتور محمد مظهر بقا، الناشر: مركز البحث العلمي وإحياء التراث الإسلامي - جامعة أم القرى الطبعة الأولى 1403.356. م4 54 محمد فال (أباه) بن عبد الله العلوي الشنقيطي. حلي التراقي من مكنون جواهر المراقي، دار الأمان_ الرباط _ المفرب ودار ابن حزم _ بيروت لبنان، الطبعة الأولى: 1438هـ_2017م. 
الشيء لو وجد لتوفرت الهمم والدواعي على نقله، فيكون هذا لازما لثبوته، فيستدل بانتفاء اللازم على انتفاء الملزوم؛ كما يعلم أنه لو لو إنا

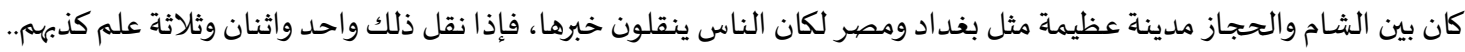

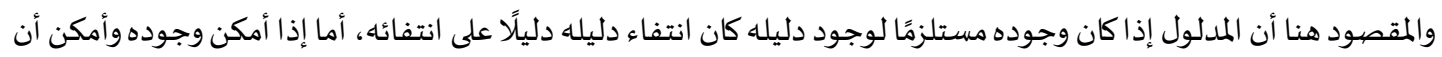

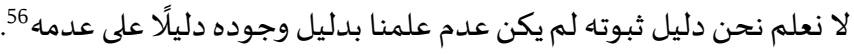

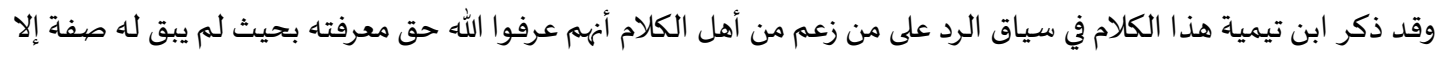

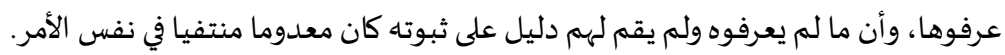

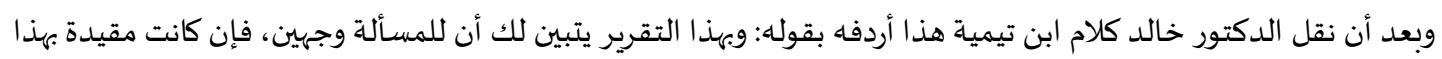

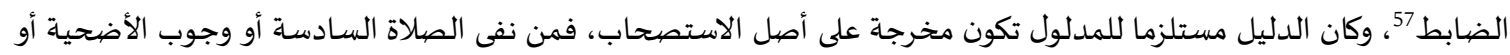

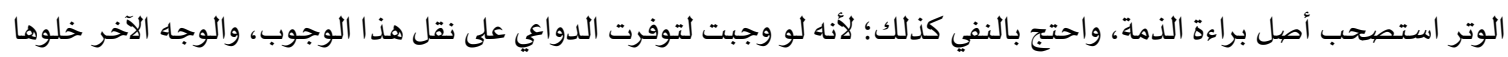

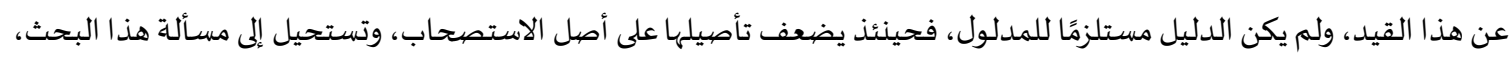

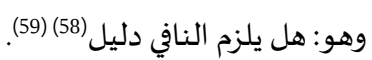
وسيأتي في المطلب الآتي مناقشة هذا الكلام.

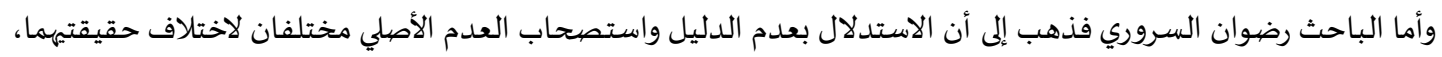

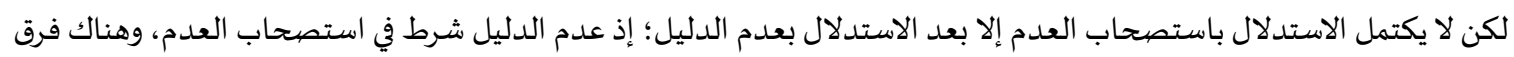

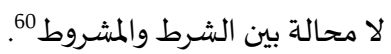
المطلب الثاني: مناقشة وترجيح: إنائ

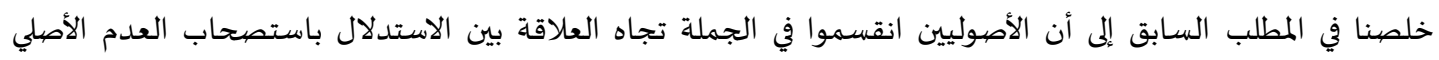

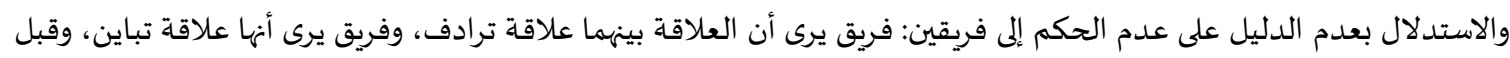

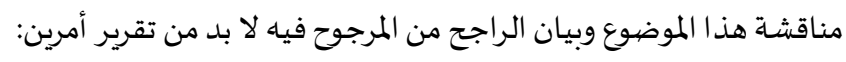

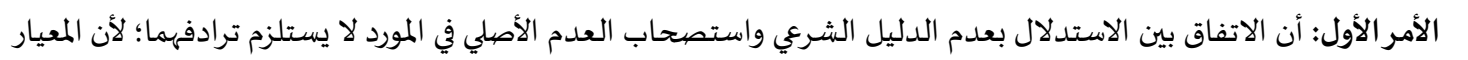

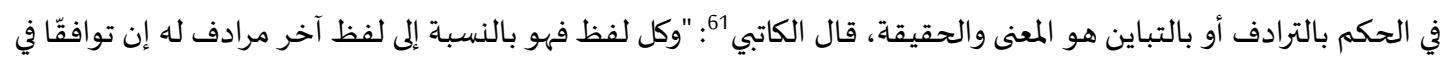

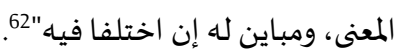

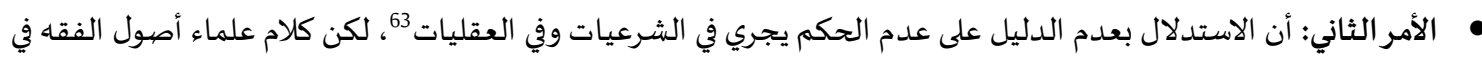

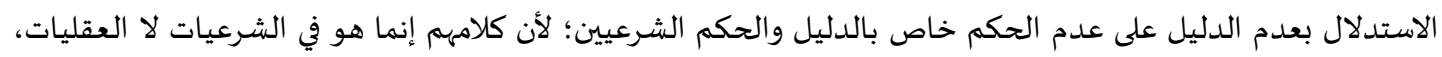

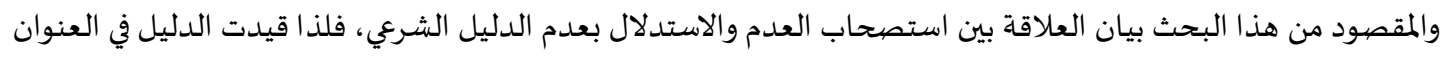
بالشرعي. وبعد تقرير هذين الأمرين أقول: إذا نظرنا إلى حقيقة الاستصحاب ندرك أنها قد لوحظت فيها الحالة السابقة، وتَقَرُرُ النفي في

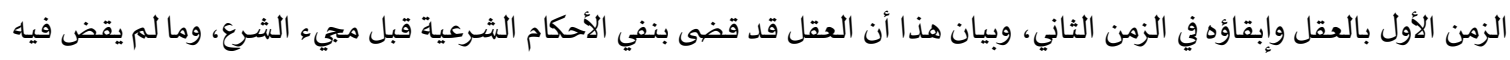

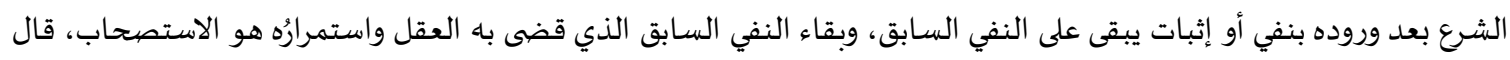

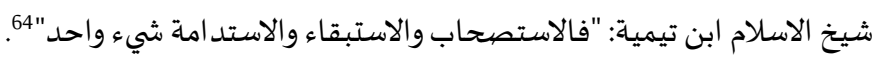

56 ابن تيمية، أحمد بن عبد الحليم. مجموع الفتاوى: $571 / 7$ وما بعدها.

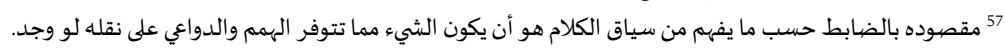

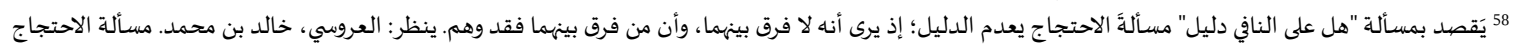
بعدم الدليل. ص: 256 و 256 وما بعدها.

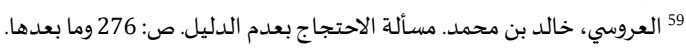

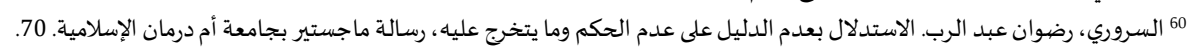

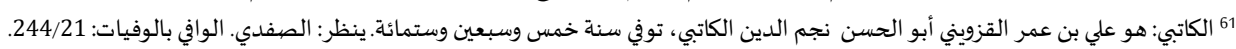

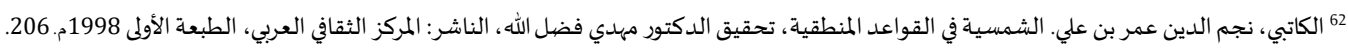

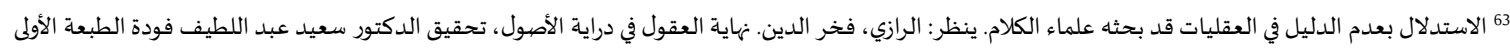

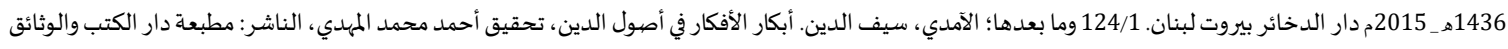

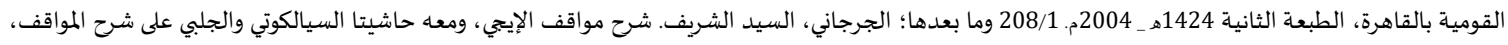

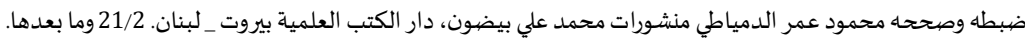
64 ابن تيمية، أحمد بن عبد الحليم. تنبيه الرجل العاقل على تمويه الجدل الباطل: 626/2. 


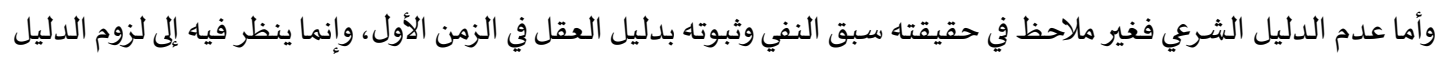

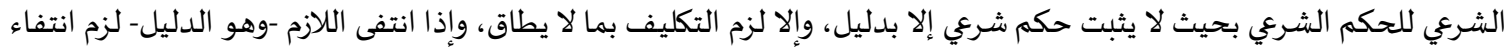

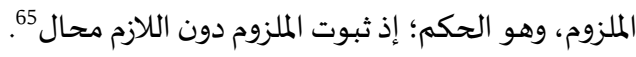

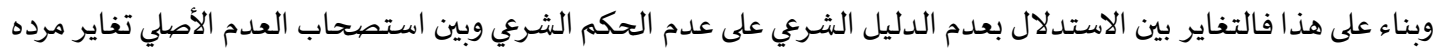

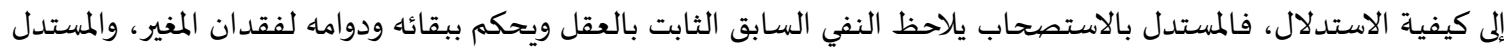

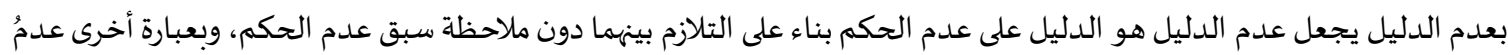

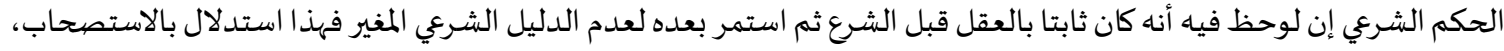

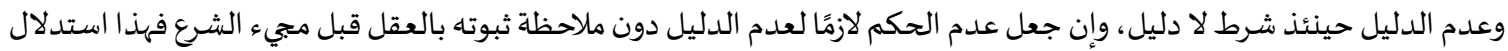

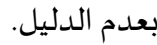

وفي نص للإمام ابن تيمية إلماع إلى هذا الفرق حيث قال وهو يتكلم على طرق الأحكام الشرعية: الطريق السادس: "الاستصحاب"

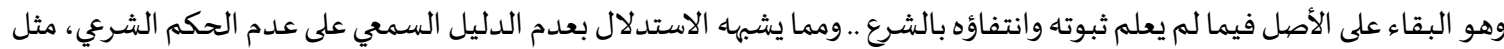

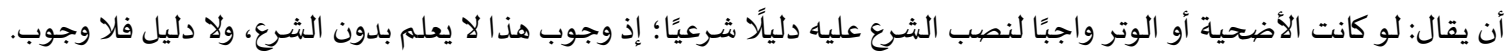

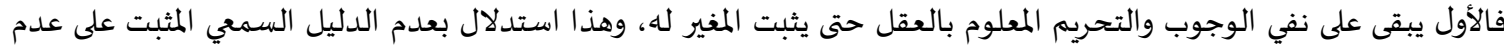

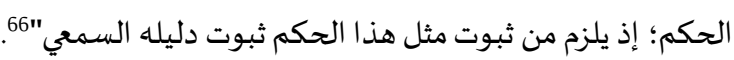

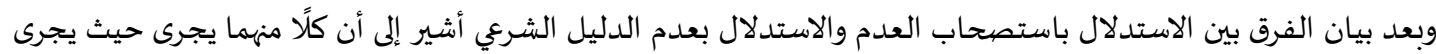

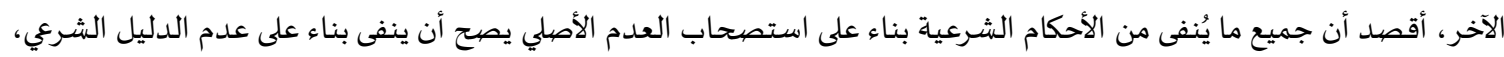

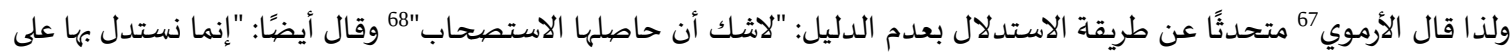

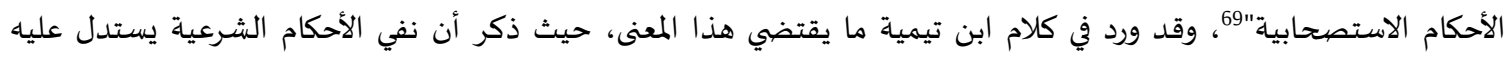
بالاستصحاب ويستدل عليه أيضا بعدم الدليل فئل فهما إذن متفقان في مورد النفي وإن تغايرا مفهومًا، ولعل هذا هو السبب في اعتبارهما عند بعض الأصوليين دليلاً واحدًا، كما أنها

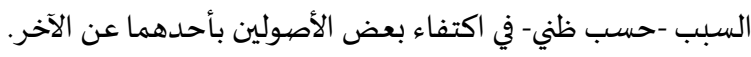

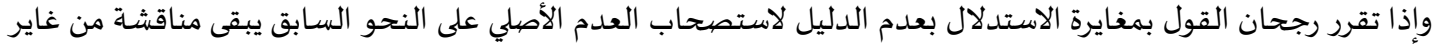

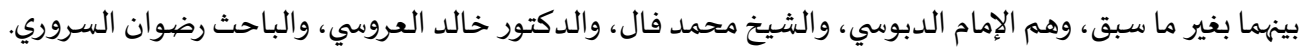

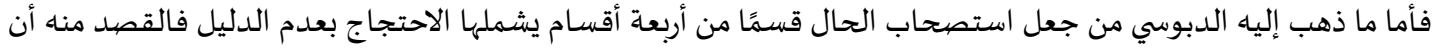

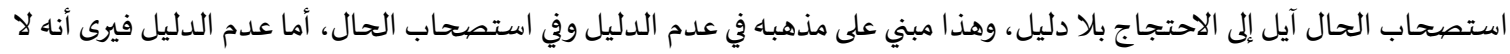

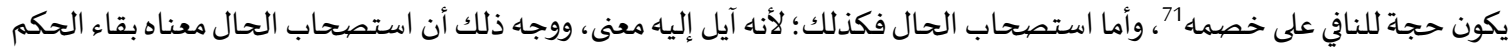

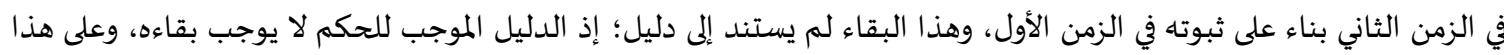

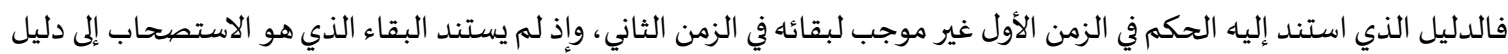

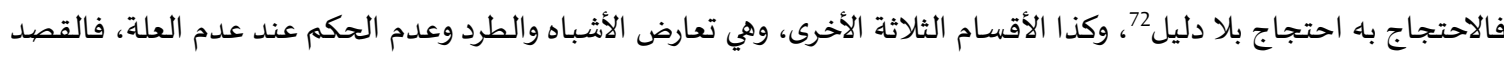

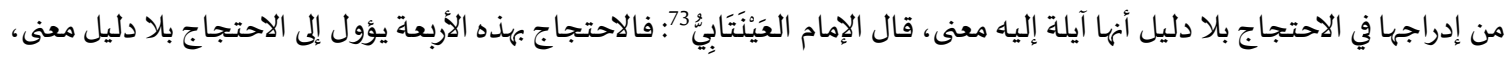

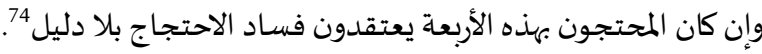

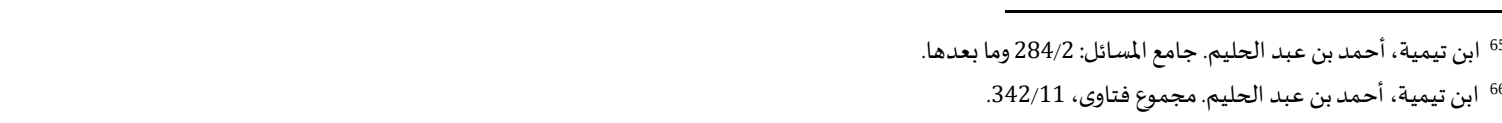

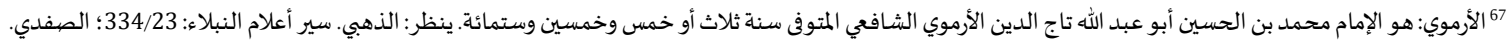
الوافي بالوفيات: 261/2. 68 الأرموي، تاج الدين أبو عبد الله محمد بن الحسين. الحاصل من المحصول في أصول الفقه، تحقيق الدكتور عبد السلام محمود أبو ناجي، الناشر: جامعة قان يونس بنغازي. .1076/2 69 الأرموي، تاج الدين. المصبدر السابق: 1078/2.

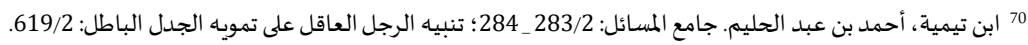

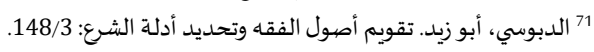

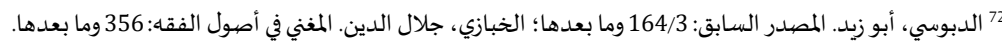

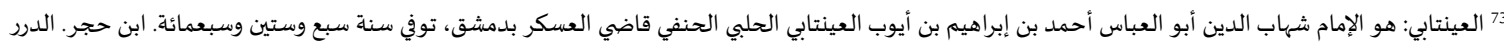

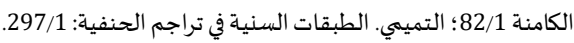

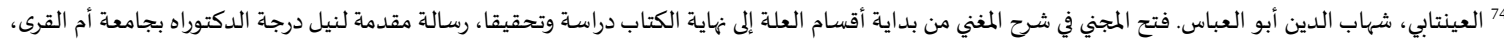
إعداد الطالبة عيدة بنت محمد حمزة الحاتهي الشريف. 219. 
وبهذا التقرير يتضح أن الدبوسي يقصد بقوله: "باب القول في جملة القائلين بلا دليل مع اعتقادهم بطلان الاحتجاج باء" أن الناج

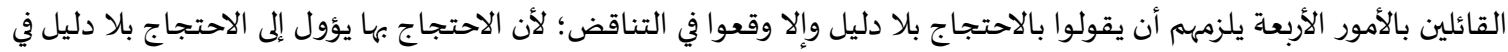

وأما ما ذهب إليه الشيخ فال -وهو أن عدم الدليل الذي هو شرط في استصحاب العدم غير عدم الدليل المعدود من الأدلة؛ لأن

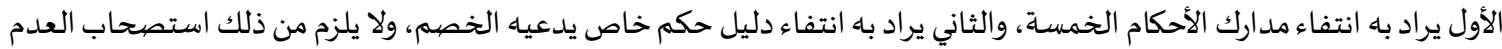

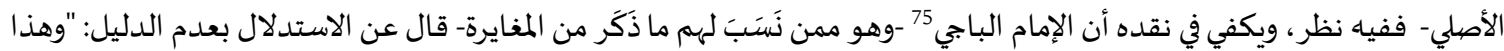

إنما هو استدلال باستصحاب الحال في براءة الذمة" ويضاف إلى ذلك أن الإمام الباجي وكثيرًا من الأصوليين قد مثلوا لاستصحاب العابداب العدم الأصلي بنفي وجوب الوتر 77، وواضح أن الدليل

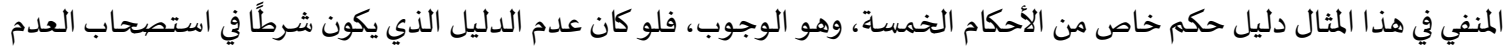

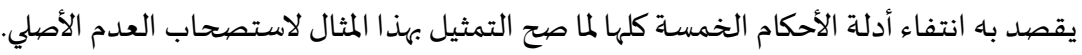
وأما ما ذكره الدكتور خالد العروسي من التحقيق الذي نسبه لابن تيمية -وهو أن المسألة إذا كانت مما تتوفر الهمم والدواعي على

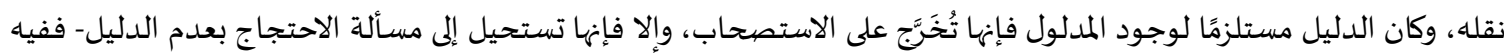
نظر من وجهين:

الأول: أن هذا الفرق الذي نسبه إلى ابن تيمية لا يدل عليه كلام ابن تيمية الذي نقله، وغاية دلالته أن عدم الدليل ليس دليلًا على عدم المدلول، إلا إذا كان المدلول مستلزمًا للدليل، مثل الأمور التي تتوفر الهمم والدواعي على نقلها لو وجدت، وهن وهذا المعنى الذي ذكره ابن تيمية في كتبه أكثر من مرة78 ليس فياه بيان للفرق الذي ذكره الدكتور العروسي. الثاني: أن ما جاء في كلامه من أن الدليل قد يكون مستلزمًا للمدلول، وحينئذ تخرج المسألة على أصل الاستصحاب، وقد يكون

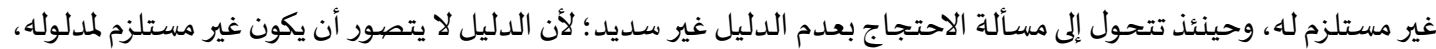

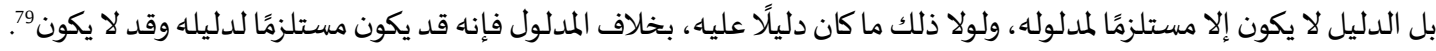
وأما ما ذكره الباحث رضوان السروري في التفريق بين عدم الدليل وبين استصحاب العدم الأصلي -وهو أن الأول شرط في في الثاني والشرط غير المشروط- فمسلم، لكنه أغفل بيان الفرق بين عدم الدليل باعتباره دلياً وبين استصحاب العدم الأصلي، وكان الأولى أن يفرق بينهما بهذا الاعتبار؛ لأن بحثه في عدم الدليل من جهة أنه دليل لا من جهاة أنه شرط.

الخاتمة:

أولًا: النتائج:

خلص البحث إلى النتائج الآتية:

عدم الدليل الشرعي لهه اعتباران: أحدهما: أنهاه شرط في استصحاب العدم الأصلي، وقد تحدث عنها الأصوليون بهذا الاعتبار ضمن حديثهم عن الاستصحاب، والثاني: أنه دليل منتج لعدم الحكم الشرعي، وقد تحدث عنداء بهذا الاعتبار كثير من الأصوليين في مبحث الأدلة المختلف فيها، والمقصود بالذات في هذا البحث عدم الدليل بالاعتبار الثاني. •اختلف الأصوليون في النسبة بين الاستدلال بعدم الدليل الشرعي وبين استصحاب العدم الأصلي على أقوال يمكن إرجاعها إجمالًا

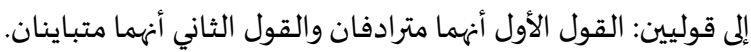
خلص البحث إلى رجحان القول بالتباين بينهما لكن على النحو الآتي، وهو أن استصحاب العدم الأصلي ملاحظ في حقيقته تَقرُّرُ النفي قبل ورود الشرع بالعقل وبقاؤه بعد الشرع، والاستدلالَ بعدم الدليل غير ملاحظ فيه ذلك، فالمستدل بالاستصحاب يلاحظ

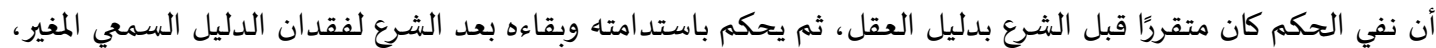

75 الباجي: هو الإمام الشهير سليمان بن خلف بن سعد بن أيوب أبو الوليد الأندلسي الباجي المالكي المتوفى سنة أربع وسبعين وأربع مائة. ينظر الذهبي. سير أعلام النبلاء: 535/15؛ الوافي بالوفيات: 229/15.

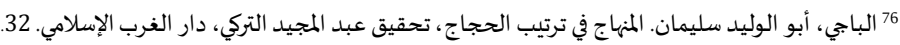

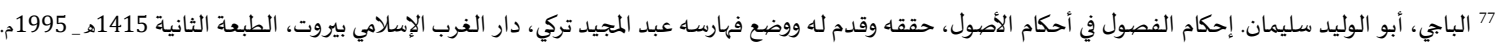

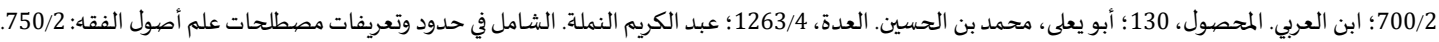

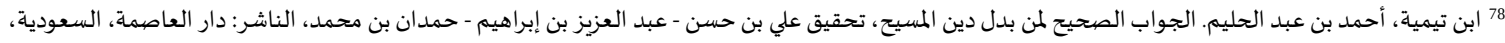

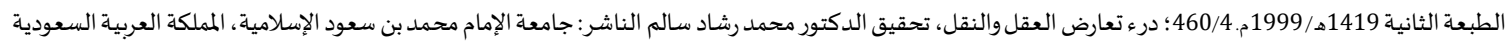

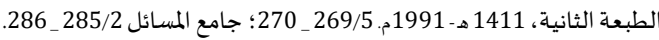
79 ابن تيمية، أحمد بن عبد الحليم. جامع المسائل 285/2؛ مجموع فتاوى ابن تيمية 142/9، و 156؛ درء تعارض العقل والنقل: 269/5 ـ 270 و 122/10. 
والمستدل بعدم الدليل لا ينظر إلى سبق النفي، بل ينظر إلى لزوم الدليل الشرعي للحكم الشرعي، بحيث لا يثبت حكم شرعي بلا

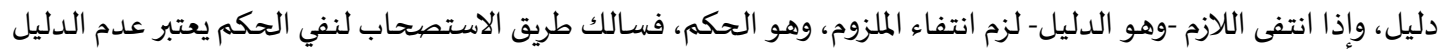

شرطا لدليله الذي هو الاستصحاب، والآخر يجعله دليلاً.

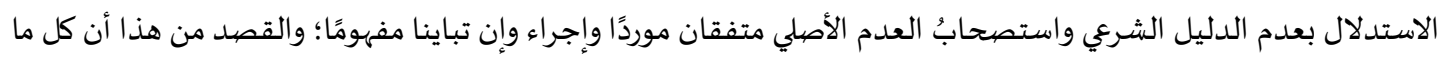

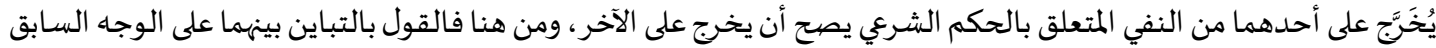

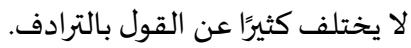

1. الأرموي، تاج الدين أبو عبد الله محمد بن الحسين (د.ت). الحاصل من المحصبول في أصهول الفقه. تحقيق الدكتور عبد السلام

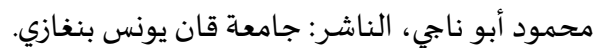
2. ابن إمام الكاملية، محمد كمال الدين (2002). تيسير الوصهول إلى منهاج الأصهول من المنقول والمعقول. دراسـة وتحقيق الدكتور

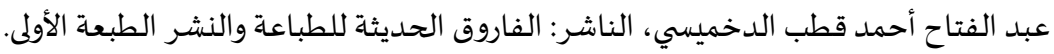
3. الآمدي، سيف الدين (2004). أبكار الأفكار في أصهول الدين. تحقيق أحمد محمد المهدي، الناشر: مطبعة دار الكتب والوثائق القومية بالقاهرة، الطبعة الثانية. 4. الآمدي، سيف الدين (2003). الإحكام في أصبول الأحكام. علق عليه عبد الرزاق عفيفي، الناشر: دار الصميعي للنشر والتوزيع

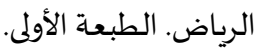
5. الباجي، سليمان أبو الوليد (1995). إحكام الفصيول في أحكام الأصهول. حققه وقدم له ووضع فهارسه عبد المجيد تركي، دار الغرب الإسلامي بيروت، الطبعة الثانياة.

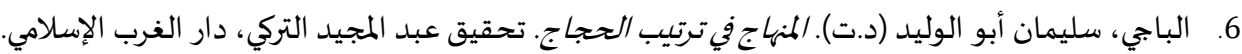

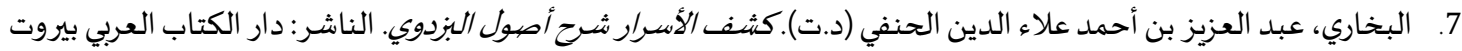
لبنان. 8. البروي، محمد بن محمد الشـافعي (2004). المقترح في المصطلح. دراسة وتحقيق وتعليق د. شريفة بنت علي بن سليمان الحوشاني، دار الوراق، الطبعة: الأولى. 9 9. البيضاوي، عبد الله بن عمر (د.ت). منهاج الوصيول إلى علهم الأصهول. اعتنى بهاه وعلق عليه محمد شيخ مصطفى، الناشر: مؤسسة الرسالة ناشرون، الطبعة الأولى. 10. التميمي، تقي الدين بن عبد القادر الحنفي (1989). الطبقات السنية في تراجم الحنفية. تحقيق عبد الفتاح محمد الحلو، الناشر: دار الرفاعي وهجر، الطبعة الأولى. 11. ابن تيمية، أحمد بن عبد الحليم (1999). الجواب الصحيح لمن بلدل دين المسيح. تحقيق علي بن حسن - عبد العزيز بن إبراهيم

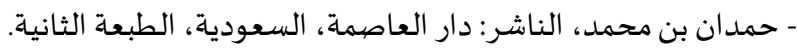

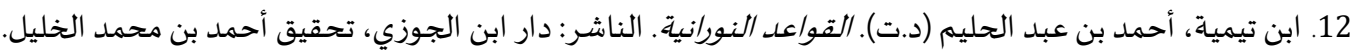

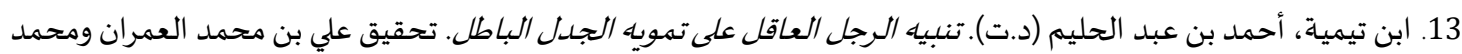
عزير شمس، إشراف بكر بن عبد الله أبو زيد، دار عالم الفوائد بنشر والتوزيع.

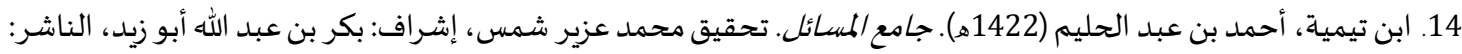
دار عالم الفوائد للنشر والتوزيع الطبعة: الأولى. 15. ابن تيمية، أحمد بن عبد الحليم (1991). درء تعارض العقل والنقل. تحقيق الدكتور محمد رشاد سالم الناشر: جامعة الإمام

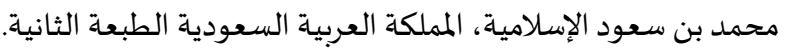
16. ابن تيمية، أحمد بن عبد الحليم (2004). مجموع الفتاوى. جمع وترتيب عبد الرحمن بن محمد بن قاسم الناشـر : مجمع الملك المكاك

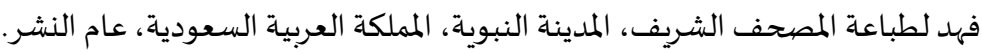
17. الجرجاني، السيد الشريف علي (د.ت). شرح المواقف للقاضي عضدل الدين عبد الرحمن الإيجي، ومعاه حاشيتا السيالكوتي

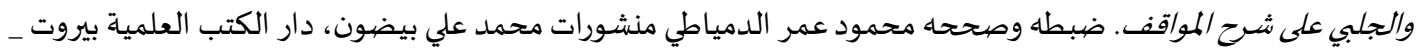


19. ابن حجر، أبو الفضل أحمد بن علي بن محمد بن أحمد (1993). الدرز الكامنة في أعيان المائة الثامنة. الناشر دار الجيل ـ بيروت.

20. أبو الحسين البصري، محمد بن علي بن الطيب المعتزلي (د.ت). المعتمد في أصول الفقه. اعتنى بتهذيبه وتحقيقه محمد حميد

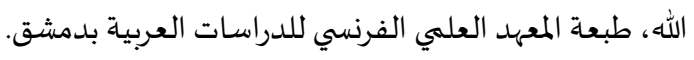

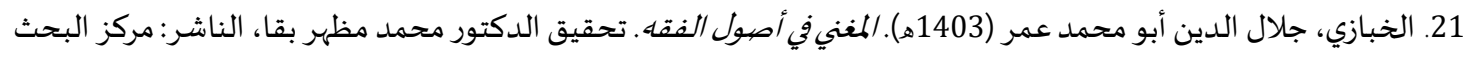
العلمي وإحياء التراث الإسلامي - جامعة أم القرى الطبعة الأولى.

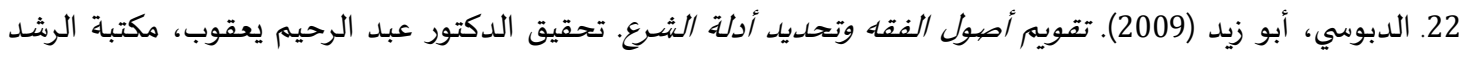
ناشرون، الطبعة: الأولى.

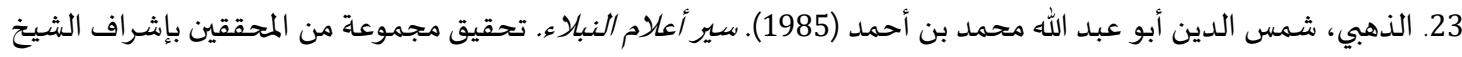
شعيب الأرناؤوط، الناشر: مؤسسة الرسالة، الطبعة: الثالثة. 24. الرازي، فخر الدين (د.ت). الكاشف عن أصول الدلائل وفصول العلل. تحقيق الدكتور أحمد حجازي السقا، دار الجيل ـ بيروت.

25. الرازي، فخر الدين (2015). نهاية العقول في دراية الأصول. تحقيق الدكتور سعيد عبد اللطيف فودة الطبعة الأولى، دار الدخائر بيروت لبنان.

26. الزركشي، بدر الدين محمد بن بهادر (1992). البحر المحيط في أصول الفينانه تحرير الشيخ عبد القادر عبد الله العاني ومراجعة

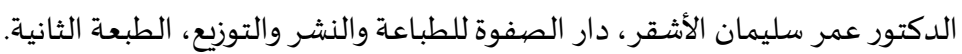

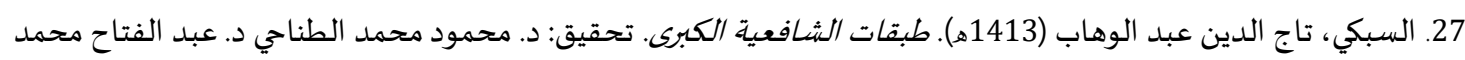
الحلو، الناشر: هجر للطباعة والنشر والتوزيع، الطبعة: الثانية.

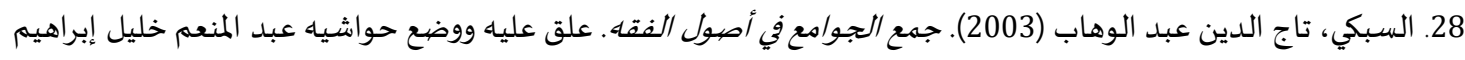
الناشر: دار الكتب العلمية بيروت _لبنان، الطبعة الثانية.

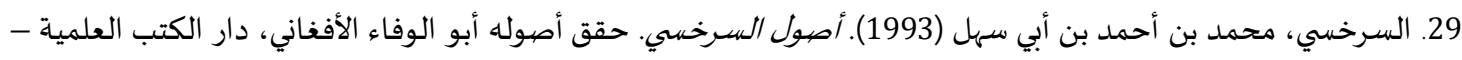

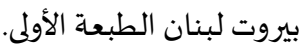

30. السروري، رضوان عبد الرب (د.ت). الاستدلال بعدم الدليل على العلى علدم الحكمم وما يتخرج عليه. رسالة ماجستير بجامعة أم درمان الإسلامية.

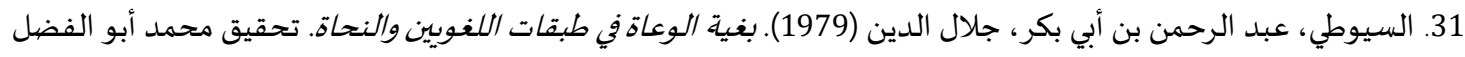
إبراهيم، الناشر: دار الفكر، ، الطبعة الثانية.

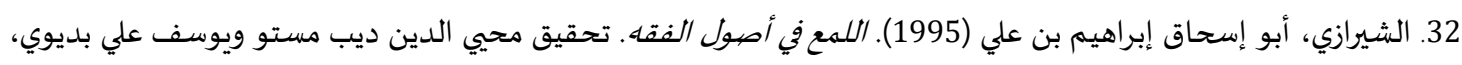

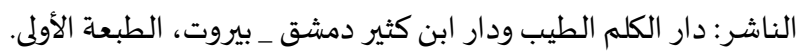

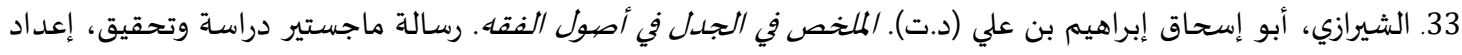

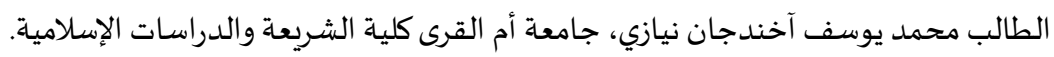

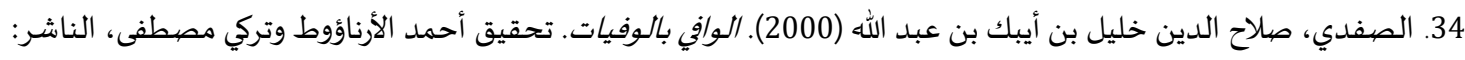
دار إحياء التراث - بيروت، الطبعة الأولى. 35. الطوفي، سليمان بن عبد القوي بن عبد الكريم (1987). شرح مختصر الروضية. تحقيق: عبد الله بن عبد المحسن التركي الناشر: مؤسسة الرسالة الطبعة : الأولى.

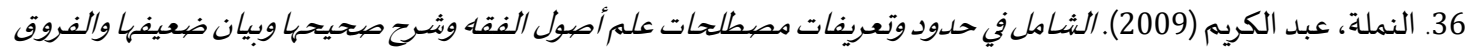

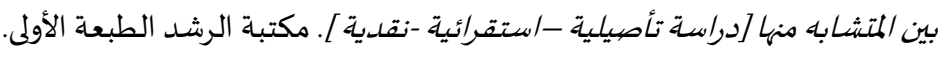

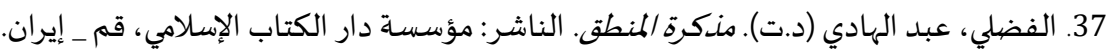

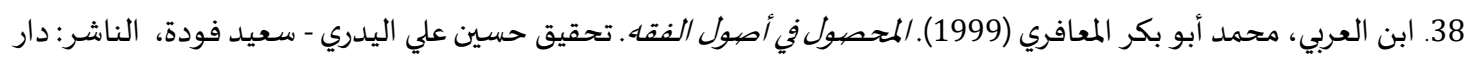

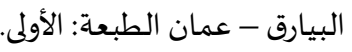

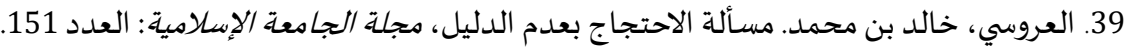

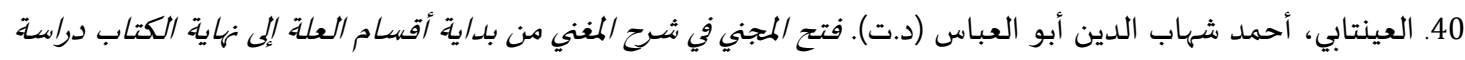

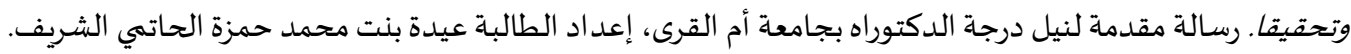


41. الغزالي، أبو حامد (1997). المستصفى من علم أصهول الفقه. تحقيق الدكتور محمد سليمان الأشقر، الناشر مؤسسة الرسالة، الطبعة الأولى.

42. ابن فارس، أبو الحسين أحمد بن فارس بن زكرياء (1979). معجمرمقاييس اللغة. تحقيق عبد السلام محمد هارون، الناشر: دار الفكر.

43. القرافي، أحمد بن إدريس أبو العباس شهاب الدين (د.ت). شرح تنقيح الفصول. الناشر: دار الفكر للطباعة والنشر والتوزيع.

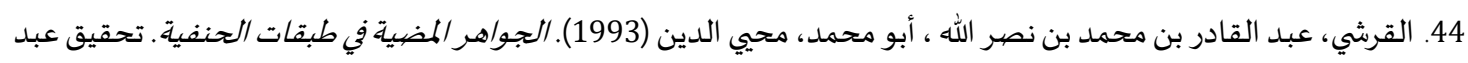

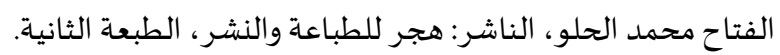

45. الكاتبي، نجم الدين عمر بن علي (1998). الشمسية في القواعد المنطقية. تحقيق الدكتور مهدي فضل الله، الناشر: المركز الثقافي العربي، الطبعة الأولى. 46. محمد فال (أباه) بن عبد الله العلوي الشنقيطي (2017). حلي التواقي من مكنون جواهر المراقي. دار الأمان_ الرباط المغرب ودار ابن حزم _ بيروت لبنان الطبعة الأولى.

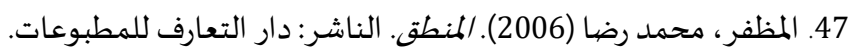

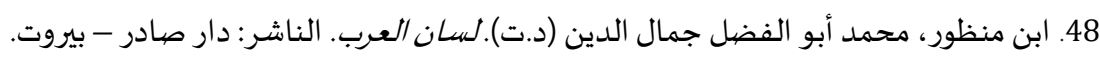

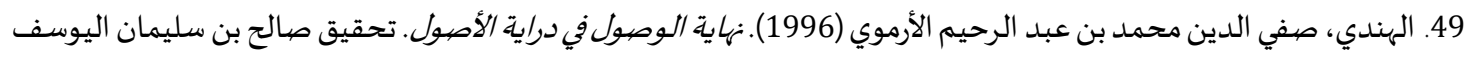

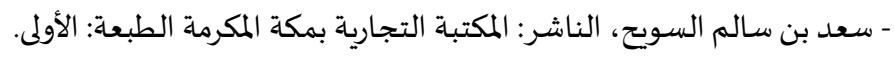

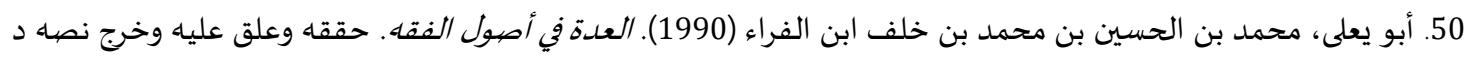
أحمد بن علي بن سير المباركي، الطبعة الثانية. 
المجلة الدولية للدراسـات الإسلامية المتخصصية

International Journal of Specialized Islamic Studies (SIS)

www.refaad.com

Journal Homepage: https://www.refaad.com/views/SIS/Home.aspx

ISSN: 2617-6246(Online) 2617-6238(Print)

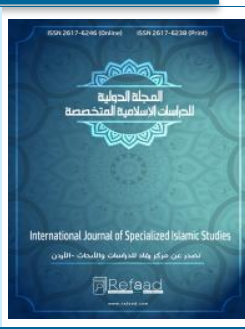

\title{
The relationship between the inference by lack of evidence and accompanying the original nothingness (Fundamentalist study)
}

\author{
Elameraouy Abdelghafour \\ Sidi Mohamed Ben Abdallah University, Fes, Morocco \\ abdelghafourelameraouy@gmail.com \\ Mohamad Rafia \\ Sidi Mohamed Ben Abdallah University, Fes, Morocco \\ Mohamad.rafia@usmba.ac.ma
}

Received: 2/10/2021 Revised: 12/10/2021 Accepted: 26/10/2021 DOI: https://doi.org/10.31559/SIS2021.6.2.4

\begin{abstract}
Inference by lack of evidence for non-judgment and accompanying the nothingness is one way of an absence of a legitimate government that is talked about fundamentalists; they are two similar and ambiguous paths. This research aims to clarify the relationship between them based on the following two questions: what the relationship between the accompanying nothingness and the inference is by lack of evidence for non-judgment and whether it is a synonym or difference. If the type of relationship between them is variance, what the difference is between them. In this study, the analytical inductive method was adopted. It was divided into two sections, in the first of them; I spoke about the concept of inference by lack of evidence for non-judgment and the idea of accompanying the original nothingness. Then I separated the talk about the relationship between them and I clarified what disagreement is in it. In the result, İ concluded that the relationship between these two concepts is a difference. The difference between them is that accompanying nothingness was the negation of the ruling in it before the Shariah as evidenced by the mind. Then I judges that it is sustainable and remains after the Shariah because there is no changer. As for the inference by lack of evidence, we do not look at the previous negation. Rather, we look at the necessity of the legal evidence for the legal ruling because it does not prove a legal ruling without evidence. If the necessary, which is the evidence, is negated, the obligatory, which is the ruling, must be compensated. I also concluded that although they are different, they are compatible in the field of negation; we mean that every annulment of every legal ruling is based on one of them may be based on the other.
\end{abstract}

Keywords: lack of evidence; lack of judgment; accompanying nothingness.

\section{References:}

1. Alarmwy, Taj Aldyn Abw 'bd Allh Mhmd Bn Alhsyn (D.T). Alhasl Mn Almhswl Fy Aswl Alfqh. Thqyq Aldktwr 'bd Alslam Mhmwd Abw Najy, Alnashr: Jam't Qan Ywns Bnghazy.

2. Alamdy, Syf Aldyn (2004). Abkar Alafkar Fy Aswl Aldyn. Thqyq Ahmd Mhmd Almhdy, Alnashr: Mtb't Dar Alktb Walwtha'eq Alqwmyh Balqahrh, Altb'h Althanyh.

3. Alamdy, Syf Aldyn (2003). Alehkam Fy Aswl Alahkam. 'lq 'lyh Alrzaq 'fyfy, Alnashr: Dar Alsmy'y Llnshr Waltwzy' Alryad. Altb'h Alawla.

4. Albajy, Slyman Abw Alwlyd (1995). Ehkam Alfswl Fy Ahkam Alaswl. Hqqh Wqdm Lh Wwd' Fharst 'bd Almjyd Trky, Dar Alghrb Aleslamy Byrwt, Altb'h Althanyh.

5. Albajy, Slyman Abw Alwlyd (D.T). Almnhaj Fy Trtyb Alhjaj. Thqyq 'bd Almjyd Altrky, Dar Alghrb Aleslamy.

6. Albkhary, 'bd Al'zyz Bn Ahmd 'la' Aldyn Alhnfy (D.T). Kshf Alasrar Shrh Aswl Albzdwy. Alnashr: Dar Alktab Al'rby Byrwt Lbnan.

7. Albrwy, Mhmd Bn Mhmd Alshaf'y (2004). Almqtrh Fy Almstlh. Drash Wthqyq Wt'lyq D. Shryfh Bnt 'ly Bn Slyman Alhwshany, Dar Alwraq, Altb'h: Alawla. 
8. Albydawy, 'bd Allh Bn 'mr (D.T). Mnhaj Alwswl Ela 'Im Alaswl. A'tna Bh W'lq 'lyh Mhmd Shykh Mstfa, Alnashr: M'sst Alrsalh Nashrwn, Altb'eh Alawla.

9. Aldbwsy, Abw Zyd (2009). Tqwym Aswl Alfqh Wthdyd Adlh Alshr'. Thqyq Aldktwr 'bd Alrhym Y'qwb, Mktbh Alrshd Nashrwn, Altb'h: Alawla.

10. Aldhby, Shms Aldyn Abw 'bd Allh Mhmd Bn Ahmd (1985). Syr A'lam Alnbla'. Thqyq Mjmw' Mn Almhqqyn Beshraf Alshykh Sh'yb Alarna'wt, Alnashr: M'sst Alrsalh, Altb'h: Althalthh.

11. Abn Emam Alkamlyh, Mhmd Kmal Aldyn (2002). Tysyr Alwswl Ela Mnhaj Alaswl Mn Almnqwl Walm'qwl. Drash Wthqyq Aldktwr 'bd Alftah Ahmd Qtb Aldkhmysy, Alnashr: Alfarwq Alhdythh Lltba'h Walnshr Altb'h Alawla.

12. Abn Hjr, Abw Alfdl Ahmd Bn 'ly Bn Mhmd Bn Ahmd (1993). Aldrr Alkamnh Fy A'yan Alma'h Althamnh. Alnashr Dar Aljyl_Byrwt.

13. Abw Alhsyn Albsry, Mhmd Bn 'ly Bn Altyb Alm'tzly (D.T). Alm'tmd Fy Aswl Alfqh. A'tna Bthdybh Wthqyqh Mhmd Hmyd Allh, Tb'h Alm'hd Al'lmy Alfrnsy Lldrasat Al'rbyh Bdmshq.

14. Aljrjany, Alsyd Alshryf 'ly (D.T). Shrh Almwaqf Llqady 'dd Aldyn 'bd Alrhmn Aleyjy, Wm'h Hashyta Alsyalkwty Waljlby 'la Shrh Almwaqf. Dbth Wshhh Mhmwd 'mr Aldmyaty Mnshwrat Mhmd 'ly Bydwn, Dar Alktb Al'lmyh Byrwt_Lbnan.

15. Aljrjany, 'ly Bn Mhmd Alsyd Alshryf (D.T). M'jm Alt'ryfat. Thqyq Mhmd Sdyq Almnshawy, Alnashr: Dar Alfdylh.

16. Alkhbazy, Jlal Aldyn Abw Mhmd 'mr (1403h). Almghny Fy Aswl Alfqh. Thqyq Aldktwr Mhmd Mzhr Bqa, Alnashr: Mrkz Albhth Al'lmy Wehya' Altrath Aleslamy - Jam't Am Alqra Altb'h Alawla.

17. Alrazy, Fkhr Aldyn (2015). Nhayh Al'qwl Fy Drayh Alaswl. Thqyq Aldktwr S'yd 'bd Alltyf Fwdh Altb'h Alawla, Dar Aldkha'r Byrwt Lbnan.

18. Alrazy, Fkhr Aldyn (D.T). Alkashf 'n Aswl Aldla'l Wfswl Al'll. Thqyq Aldktwr Ahmd Hjazy Alsqa, Dar Aljyl_ Byrwt.

19. Alsbky, Taj Aldyn 'bd Alwhab (1413h). Tbqat Alshaf'yh Alkbra. Thqyq: D. Mhmwd Mhmd Altnahy D. 'bd Alftah Mhmd Alhlw, Alnashr: Hjr Lltba'h Walnshr Waltwzy', Altb'h: Althanyh.

20. Alsbky, Taj Aldyn 'bd Alwhab (2003). Jm' Aljwam' Fy Aswl Alfqh. 'lq 'lyh Wwd' Hwashyh 'bd Almn'm Khlyl Ebrahym Alnashr: Dar Alktb Al'lmyh Byrwt_Lbnan, Altb'h Althanyh.

21. Alsrkhsy, Mhmd Bn Ahmd Bn Aby Shl (1993). Aswl Alsrkhsy. Hqq Aswlh Abw Alwfa' Alafghany, Dar Alktb Al'lmyh - Byrwt Lbnan Altb'h Alawla.

22. Alsrwry, Rdwan 'bd Alrb (D.T). Alastdlal B'dm Aldlyl 'la 'dm Alhkm Wma Ytkhrj 'lyh. Rsalt Majstyr Bjam't Am Drman Aleslamyh.

23. Altmymy, Tqy Aldyn Bn 'bd Alqadr Alhnfy (1989). Altbqat Alsnyh Fy Trajm Alhnfyh. Thqyq 'bd Alftah Mhmd Alhlw, Alnashr: Dar Alrfa'y Whjr, Altb'h Alawla.

24. Abn Tymyh, Ahmd Bn 'bd Alhlym (1999). Aljwab Alshyh Lmn Bdl Dyn Almsyh. Thqyq 'ly Bn Hsn - 'bd Al'ezyz Bn Ebrahym - Hmdan Bn Mhmd, Alnashr: Dar Al'asmh, Als'wdyh, Altb'h Althanyh.

25. Abn Tymyh, Ahmd Bn 'bd Alhlym (D.T). Alqwa'd Alnwranyh. Alnashr: Dar Abn Aljwzy, Thqyq Ahmd Bn Mhmd Alkhlyl.

26. Abn Tymyh, Ahmd Bn 'bd Alhlym (D.T). Tnbyh Alrjl Al'aql 'la Tmwyh Aljdl Albatl. Thqyq 'ly Bn Mhmd Al'mran Wmhmd 'zyr Shms, Eshraf Bkr Bn 'bd Allh Abw Zyd, Dar 'alm Alfwa'd Bnshr Waltwzy'.

27. Abn Tymyh, Ahmd Bn 'bd Alhlym (1422h). Jam' Almsa'l. Thqyq Mhmd 'zyr Shms, Eshraf: Bkr Bn 'bd Allh Abw Zyd, Alnashr: Dar 'alm Alfwa'd Llnshr Waltwzy' Altb'h: Alawla.

28. Abn Tymyh, Ahmd Bn 'bd Alhlym (1991). Dr' T'ard Al'ql Walnql. Thqyq Aldktwr Mhmd Rshad Salm Alnashr: Jam't Alemam Mhmd Bn S'wd Aleslamyh, Almmlkh Al'rbyh Als'wdyh Altb'h Althanyh.

29. Abn Tymyh, Ahmd Bn 'bd Alhlym (2004). Mjmw' Alftawa. Jm' Wtrtyb 'bd Alrhmn Bn Mhmd Bn Qasm Alnashr: Mjm' Almlk Fhd Ltba'h Almshf Alshryf, Almdynh Alnbwyh, Almmlkh Al'rbyh Als'wdyh, 'am Alnshr.

30. Alzrkshy, Bdr Aldyn Mhmd Bn Bhadr (1992). Albhr Almhyt Fy Aswl Alfqh. Thryr Alshykh 'bd Alqadr 'bd Allh Al'any Wmraj't Aldktwr 'Emr Slyman Alashqr, Dar Alsfwh Lltba'h Walnshr Waltwzy', Altb'h Althanyh. 